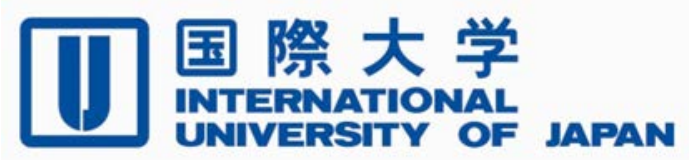

Economics \& Management Series

EMS-2017-05

\title{
The Future Prospect of the Long-term Care Insurance in Japan
}

Ryuta Ray Kato

International University of Japan

October 2017

IUJ Research Institute

International University of Japan

These working papers are preliminary research documents published by the IUJ research institute. To facilitate prompt distribution, they have not been formally reviewed and edited. They are circulated in order to stimulate discussion and critical comment and may be revised. The views and interpretations expressed in these papers are those of the author(s). It is expected that the working papers will be published in some other form. 


\title{
The Future Prospect of the Long-term Care Insurance in Japan *
}

\author{
Ryuta Ray Kato ${ }^{\dagger}$
}

\section{October 2017}

\begin{abstract}
This paper explores the impact of population aging on the Japanese public longterm care insurnace (LTCI) within a numerical dynamic general equilibrium model with multiple overlapping generations. The impact of three policy options, such as an increase in co-payments, an earlier starting age of contribution, and more distribution of the cost to the public sector, is also examined. The numerial results show that in the next about forty years the burdens on the first (age 65 and over) and second (age 40 to 64 ) groups become more than 1.7 times and more than 2.7 times as much, respectively. A relatively more increase in the burdens on the second group cannot be avaiodable, even if adjustment of the cost distribution between both groups is made every three years in the future in accordance with the schedule by the MHLW. Furthermore, in order to reduce future burdens in the LTCI, an increase in co-payments is most preferable, rather than an earlier starting age of contribution in longer duration of contribution with lower burdens every year, or a shift of the cost to the public sector followed by a very higher consumption tax.
\end{abstract}

Keywords: Long-term Care Insurance, Population Aging, Japan, Simulation

JEL Classification: C68, H51, E62, H55, and J16

\footnotetext{
*Grant-in-Aid for Scientific Research by Japan Society for the Promotion of Science (No. 15K03525) is acknowledged.

${ }^{\dagger}$ Graduate School of International Relations, International University of Japan, 777 Kokusai-cho, MinamiUonuma, Niigata 949-7277, Japan (email: kato@iuj.ac.jp).
} 


\section{Introduction}

This paper explores the impact of population aging on the Japanese public long-term care insurance (LTCI) within a numerical dynamic general equilibrium model with multiple overlapping generations.

In the rapidly growing literature on population aging of Japan within the framework of Auerback and Kotlikoff (1987), the impact of population aging on public schemes such as the national health services, public pension, and the public long-term care insurance (LTCI) has been examined (Ihori et al (2011), Kitao(2015a, 2015b, and 2017), and Brown and Joines $\left.(2015)^{1}\right)$. In particular, Braun and Joines (2015) examined public medical benefits, which can be interpreted as benefits through the national health services and the LTCI, and Kitao (2015a) separated the LTCI from the national health services explicitly. This paper further expands the literature by taking into account more realistic aspects of the actual LTCI within the framework of Auerback and Kotlikoff (1987), and it also discusses three possible policy options, all of which have been considered in actually ongoing arguments particularly in policy making environments; an increase in co-payments by the elderly who obtain elderly care services through the LTCI, a wider coverage of contributing cohorts, and a change in the cost distribution between the public sector and the insured. The elderly currently has to co-pay a $10 \%$ of the total cost when the elderly uses elderly care services through the LTCI, and the impact of an increase in the co-payment rate is explored. As the second option, a change in a coverage of contributing cohorts is examined. Under the current scheme, all cohorts have to contribute to the scheme when they become age 40. Cohorts between age 40 and 64 compulsorily belong to the second group (age 40 to 64 ), and then they will move to the first group (age 65 and over), once they become age 65. In this option, a starting age to be in the second group becomes earlier from age 40 to 30 or 35 , so that all cohorts

\footnotetext{
${ }^{1}$ Hansen and İmrohoroğlu (2016) examined the impact of population aging on fiscal imbalance in Japan in their neoclassical model. İmrohoroğlu and Sudo (2010) suggested a drastic cut of government expenditures in Japan within the standard growth model. İmrohoroğlu et al (2016) used the large-scale overlapping generations model for Japan to paricularly discuss the impact of population aging on the public pension account.
} 
start contributing to the LTCI earlier. The last option is on the distribution of the cost between the public sector and the insured. Currently, the remaining total cost after paid by the insured as co-payments is equally distributed between the public sector (50\%) and the insured $(50 \%)^{2}$. In this last option, the equal distribution is modified.

A novel feature of this study is that this paper uses the framework of Auerback and Kotlikoff (1987) to substantially examine the long-term care insurance (LTCI) in a graying Japan. A simulation analysis must take into account realistic aspects as much as it can. First, the latest population projection by the National Institute of Population and Social Security Research (IPSS) (2017) is used for future demographics. The past population data is also used as much as possible. Second, several assumptions on the future economic environment given in the latest version of Economic and Fiscal Projections for Medium to Long-term Analysis (EFPMLA: January 2016) are used to specify the future economy such as primary balance and future government deficits ${ }^{3}$. EFPMLA (2016) numerically embodies the so-called growth strategy, the main policy of Abenomics, and this paper tries to examine to the extent how much assumptions given in Abenomics are realistic within the framework of Auerback and Kotlikoff (1987) with the latest population projection. Third, the future path of already highly accumulated public pension fund is assumed to follow the assumption by the Ministry of Health, Labor and Welfare (MHLW). Fourth, the general account, the public pension account, and the long-term care insurance (LTCI) are separately considered explicitly in order to reflect reality. Realistic structures of the contribution and replacement rates in the public pension as well as of the cost distribution in the LTCI are also taken into account in numerical experiments.

Several numerical results are obtained as follows: First, as other empirical studies suggest,

\footnotetext{
${ }^{2} \mathrm{~A} 10 \%$ of the total cost is initially paid as co-payments by the elderly who used the services through the LTCI. Then the remaining total cost, which is a $90 \%$ of the initial total cost, is equally paid by the public sector and by the insured. A $50 \%$ of the remaining cost is further devided between the insured of the first and secong groups according to population aging.

${ }^{3}$ Using the older version of EFPMLA (2014), Miyazawa and Yamada (2015) examined the growth strategy of Abenomics within the framework of Auerback and Kotlikoff (1987), and they concluded that the growth strategy seems difficult to be achieved even under very optimistic assumptions made in EFPMLA (July 2014).
} 
population aging leaves more burdens on the LTCI. Both the first group (age 65 and over) and the second group (age 40 to 64 ) have to pay more cost. In the next about forty years, the burdens on the first and second groups become more than 1.7 times and more than 2.7 times as much, respectively. A relatively more increase in the burdens on the second group cannot be avoidable, even if adjustment of the cost distribution between both groups is made every three years in the future in accordance with the schedule by the MHLW. This is because the relative size of cohorts between age 40 and 64 to the size of the first group of age 65 and over drastically decreases, so that the cohorts between age 40 and 64 further have to pay the increasing cost caused by population aging. Since cohorts which basically obtain elderly care services through the LTCI belong to the first group, the second group further has to support the first group through the LTCI in a graying Japan. The intergenerational transfer mechanism exists in the LTCI. Second, among three possible policy options, a policy of an increase in co-payments is most preferable among all three options. This implies that all cohorts most prefer the case where they pay the cost by themselves when they need services through the LTCI, rather than the policy of longer duration of contribution or the policy of more distribution of the cost to the public sector followed by a higher consumption tax. Third, if a policy to increase co-payments is not available, then, as the second best policy, almost all cohorts choose a policy of distribution of a $60 \%$ of the cost to the public sector with a relatively slight increase in a consumption tax. However, particularly future cohorts do not prefer a policy with too much distribution of the cost to the public sector, since such a policy is followed by a very high consumption tax. Finally, while an earlier starting age of contribution of age 35 is the third best policy option for future cohorts, a too early starting age of contribution of age 30 is least preferable among all policy options even for future cohorts, while such a policy induces quite low burdens per year. This implies that cohorts do not prefer too long duration of contribution with much lower burdens per year ${ }^{4}$. These

\footnotetext{
${ }^{4} \mathrm{As}$ it is shown in the section of numerical resutls, this does not imply that each cohort does not prefer longer duration of contribution with lower burdens per year. Indeed, almost all cohorts prefer longer duration of contribution with lower burdens per year compared to the current scheme.
} 
results show that cohorts prefer to pay the cost by themselves when they obtain elderly care services through the LTCI, rather than sharing the cost through their life in a very long duration of contribution to the LTCI, or paying the cost with a very high consumption tax.

This paper is organized as follows. The next two sections review the background of population aging and the literature. Then Section 4 introduces the model in detail. Section 5 explains calibration, and Section 6 presents numerical results in detail. Section 7 concludes the paper.

\section{Population Aging}

It is the common knowledge that the financial circumstances for the LTCI will become more severe in a graying Japan. The National Institute of Population and Social Security Research (IPSS) released the latest population projection of Japan in year 2017. Figures 1 shows the difference in the dependency ratio between the last projection of year 2012 and the latest projection of year 2017, respectively ${ }^{5}$. The dependency ratio is defined as the ratio of age 65 and over to the total number of age 20 to age 64 . Note that the IPSS also releases the projected demographic structure for another 50 years in each projection as a reference estimate in the projections ${ }^{6}$. In the figure, all values have been obtained from the projections by the IPSS.

While the figure shows that the latest projection was made based on a slightly optimistic assumption, population aging in Japan is still rapid and high enough for currently on-going arguments. Even under the relatively optimistic assumption made in the latest projection of year 2017, the total population is expected to shrink to less than 60 million in the next 100 years. Reflecting rapid population aging, the surrounding environment of the LTCI will become more severe in a graying Japan.

\footnotetext{
${ }^{5}$ In the figure, the actual data has been used until year 2010 for the projection of year 2012 and until year 2015 for the projection of year 2017. On the future projected values, the midium variant values of the fertily rate as well as of the death rate are used for both projections.

${ }^{6} \mathrm{~A}$ reference estimate for another 50 years in the last projection of year 2012 starts from year 2061, and also that in the latest projection of year 2017 starts from year 2066.
} 


\section{The Literature}

The literature on the Japanese LTCI mainly consists of empirical studies. Yamada et al (2006) reviewed the LTCI scheme, and also estimated key determinants in decision making by the elderly between nursing home care and community-based formal/informal home care through the LTCI. Mitchell et al (2008) focused on patterns in the LTCI use, and examined the factors associated with the LTCI utilization patterns. Mitchell et al (2008) found that elderly consumers prefer the subsidized LTCI, particularly home care with the LTCI, to hospitalization, and also that regional disparities in terms of entitlement and care use persist and the disparities are likely to grow. Ohwa and Chen (2012) provided an overview of the LTCI scheme from the perspective of balancing the provision and financing of care. Shimizutani (2014) reviewed a decade of implementation of the LTCI, and also examined official future projections of the cost in the LTCI as well as assumptions in the projections. Shimizutani (2014) also proposed a micro-based approach which considers diversity, incentive mechanisms, and inter-generational differences for reforms of the scheme. Shirasawa (2015) overview the LTCI scheme, and proposed promotion of integrated community care system to cope with shortage of funding and also securing care workers. Tanaka (2016) estimated the mortality ratio by care class in the LTCI, and proposed a redesign of the public pension benefit structure by introducing the care pension, which provides LTCI beneficiaries a pension increase to compensate for LTCI self-payment according to their care class.

In the existing literature on the Japanese LTCI, estimation of the long term cost of the LTCI has also been a main issue. Ueda et al (2014) and Tajika and Kikuchi (2014) estimated the long term cost of the long-term care insurance, and both concluded that the increasing trend of the cost cannot be avoidable due to population aging in Japan. European commission (2015) reported that the increasing trend of the cost of the long-term care among member countries continues. Akimura (2016) used the same estimation method as European Commission (2015) to estimate the cost of the long-term care insurance in Japan, and also concluded the unavoidable increasing trend of the cost of the long-term care insurance in a 
graying Japan.

While the existing studies employ empirical methods, this paper examines the LTCI in a dynamic general equilibrium model with optimal decision behaviors. This paper uses the framework of Auerback and Kotlikoff (1987). Since Homma et al (1987) applied Auerbach et al (1983) to the Japanese context to examine the impact of the tax reform, the framework of Auerback and Kotlikoff (1987) has developed substantially for examining population aging of $\operatorname{Japan}^{7}$. Braun and Joines (2015) recently experimented the impact of different future fertility rates, thus different future population structures, on the schemes of public pension and national health services within their forward looking model. Kitao (2015a) used the dynamic programming (DP) method in her model, and considered the long-term care insurance scheme separately, taking into account endogenous labor supply in both intensive and extensive margins with income shocks.

In the recently growing literature on population aging in Japan within the framework of Auerback and Kotlikoff (1987), there are several common assumptions. First, they all use the population projection of year 2012, and also only use the values up to year 2060 . Then, they impose several assumptions on the future demographics after year 2060, all of which basically result in the stable demographics with the low aging rate and the dependency ratio in the future eventually. However, as Figure 1 shows, the population projection of year 2017 with a reference estimate up to year 2115 by the IPSS shows the stable demographics with the very high aging rate and dependency ratio. Obviously, such future demographics indicates more pessimistic results in comparison with recent studies. In the population projection of year 2017, the total population of each cohort from age 0 to 100 from year 2016 to year 2065 is available in the usual estimate. Furthermore, the figures from year 2066 to 2115 are also available as a reference estimate. This paper uses both estimates for specification of parameter values of fertility and mortality rates of each cohort from year 2016 to year 2115. On the past value, the actual demographic data is used for specification from year

\footnotetext{
${ }^{7}$ See Kato (2017) for the detailed review of the recent literature on population aging in Japan.
} 
1920 to year 2015. Second, although the general account, the pension account, and the long-term care insurance account in the government budget are all separately operated in reality $^{8}$, many studies have simple assumptions with an integrated budget constraint of the government. This paper explicitly considers separated budget constraints with transfers between different accounts, by particularly paying attention to the actual LTCI. Third, several assumptions on the future government deficits and the public pension fund seem unrealistic and sometime unspecified clearly in the recent literature. The assumption on the future paths of government deficits and the public pension fund does matter for the argument on fiscal imbalance of public schemes. This paper tries to follow the assumptions on the future environment given in Abenomics as close as possible.

This paper expands Kitao (2015a) by incorporating more realistic aspects of the LTCI with the latest population projection of year 2017 within the model of Kato (2017), and also examines three possible policy options; an increase in co-payments by the elderly, a wider coverage of contributing cohorts, and a change in the cost distribution between the public sector and the insured. The elderly currently has to co-pay a $10 \%$ of the total cost when the elderly uses elderly care services through the LTCI, and the impact of an increase in the co-payment rate is explored. As the second option, a change in a coverage of contributing cohorts is examined. Under the current scheme, all cohorts have to contribute to the scheme when they become age 40 . Cohorts between age 40 and 64 compulsorily belong to the second group (age 40 to 64), and then they will move to the first group (age 65 and over), once they become age 65 . In this option, a starting age to be in the second group becomes earlier from age 40 to 30 or 35, so that all cohorts start contributing to the LTCI earlier. Indeed, this is one of the options which has currently been argued in actually ongoing discussions. The last option is on the distribution of the cost between the public sector and the insured. Currently, the remaining total cost after paid by the insured is equally distributed between the public sector $(50 \%)$ and the insured (50\%). In this last option, the equal distribution

\footnotetext{
${ }^{8}$ Several transfers between accounts in reality must be mentioned.
} 
is modified.

\section{The Model}

\subsection{Demographic Structure}

An overlapping generations economy in discrete time with a model period of one year is considered $^{9}$. The representative household in each cohort appears in the economy at age 20 as a decision maker. Although the household faces uncertainty regarding its death in each period, it dies with certainty at the end of its age of 99 if it is alive until age 99 . It is assumed that there is no uncertainty regarding the size of the total population in each period. Denote the survival rate by $P_{s}$, which is defined by $P_{s}=\prod_{i=1}^{s} q_{i}$, where $q_{j+1}$ is the conditional survival rate of a $j$ years old household which survives to $j+1$ years old. Due to uncertainty of lifetime in each period, accidental/unintended bequests generated by death of all cohorts exist in each period, and such bequests are distributed to the surviving household in a particular age. Denote the pre-taxed amount of accidental/unintended bequests inherited in age $s$ at time $t$ by $b q_{s, t}$, and each cohort receives the net bequests denoted by $\left(1-\tau_{q, t}\right) b q_{s, t}$ once in its life, where $\tau_{q, t}$ is the inheritance tax rate at time $t$. No bequest motives are assumed so that the representative household of each cohort enters an economy with no assets. No liquidity constraint is imposed. The age-specific fertility and mortality rates are time variant, both of which are calculated based on the actual past data and the projection of year 2017 by the IPSS. This implies each cohort has different fertility and mortality rates over time, and $P_{s}$ differs among different cohorts.

\subsection{The Representative Household}

The representative household in each cohort is forward-looking, and future events affect decisions made today. The representative household faces lifetime uncertainty in each period,

\footnotetext{
${ }^{9}$ This paper uses the basically same model as Kato (2017) for analyzing the Japanese LTCI.
} 
but there is no other uncertainty such as an income shock through its lifetime ${ }^{10}$. The representative household consists of four different types of workers. Workers differ, depending on the gender as well as the types of the job contract. Workers are differentiated by the difference in their job types with their employer; regular workers (Seiki koyo) and nonregular workers (Hi-Seiki koyo). The latter workers include part-time, dispatched, or fixed term workers. Thus, there are four different workers in the representative household in each cohort; male regular, female regular, male non-regular, and female non-regular workers, respectively. While the representative household consists of four different workers, there is no heterogeneity in terms of preference among them, and the representative household in each cohort is assumed to have unitary preference ${ }^{11}$.

The representative household is assumed to maximize its expected lifetime utility with respect to its own consumption and leisure time. The household's expected lifetime utility of cohort $g$, denoted by $E\left[V_{g}\right]$, is given

$$
E\left[V_{g}\right]=\sum_{s=20}^{99} P_{s}(1+\delta)^{-(s-20)} \frac{u\left(c_{s, t}, l_{s, t}\right)^{1-\rho}}{1-\rho}
$$

where $\rho$ is a reciprocal of the elasticity of substitution between consumption at the different time. $\delta$ is the time preference. $c_{s, t}$ and $l_{s, t}$ are consumption and leisure of a $s$ years old household at time $t$, respectively. Note that there is a relationship of $t=g+s$. The felicity function of $u$ is given by:

$$
u\left(c_{s, t}, l_{s, t}\right)=\left[c_{s, t}^{\frac{\xi-1}{\xi}}+\kappa l_{s, t}^{\frac{\xi-1}{\xi}}\right]^{\frac{\xi}{\xi-1}},
$$

where $\xi$ denotes the elasticity of substitution between consumption and leisure, and $\kappa$ denotes the weight parameter for leisure.

\footnotetext{
${ }^{10}$ If there is also uncertantiy in lifetime wage income, then precautionary savings motives exist. Thus, with the assumption of no income shocks, the magnitude of the impact of any policy change on savings, thus on the capital labor ratio, will be smaller. However, qualitative results should not be affected.

${ }^{11}$ For simplicity, the collective approach to modelling the household is not adopted. See Basu (2006) and Agenor (2017) for the collective approach.
} 
The budget constraint of the representative household is:

$$
\begin{aligned}
a_{s+1, t+1} & =\left[1+\left(1-\tau_{r, t}\right) r_{t}\right] a_{s, t}+\left(1-\tau_{w, t}-\tau_{p, t}-\tau_{e, s, t}\right) e_{s}\left(1-l_{s, t}-l c_{s, t}-l e_{s, t}\right) w_{t} \\
& +\left(1-\tau_{w, t}\right) b_{s, t}+d_{s, t}+\left(1-\tau_{q, t}\right) b q_{s, t}-\left(1+\tau_{c, t}\right) c_{s, t}-h_{s, t}-I C_{s, t}-\theta_{t} L T_{s, t}
\end{aligned}
$$

where $a_{s, t}$ is the amount of assets held by a $s$ years old household at the beginning of time $t . e_{s}$ is the measure of efficiency of labor of the household, and $e_{s}$ is the weighted average of efficiency of four different workers. Note that efficiency is different in age among all four different workers as well. $l c_{s, t}$ and $l e_{s, t}$ denote the time spent on child rearing and elderly care, respectively, both of which are assumed to be exogenously given to the household. $d_{s, t}$ and $h_{s, t}$ denote a financial child allowance given by the government and the financial cost of child rearing in age $s$ at time $t$, respectively. The representative household in each cohort is assumed to have the average number of children when it becomes age 28 (the age of its child is 0$)^{12}$. As expressed by (1), the representative household does not have any utility from having a child. It starts rearing its own child until its child becomes age 20, thus until its own age of $48^{13}$. To reflect reality, a financial child allowance is given to the representative household by the time when its own child becomes age 15 . This implies that the representative household in each cohort receives a child allowance between its own ages of 28 and 43, while it has to pay the financial child rearing cost until its own age of 48 . The actual data of $d_{s, t}$ from Cabinet Office of Japan is used to specify the value in the model ${ }^{14}$. On the value of $h_{s, t}$, the study on the financial cost of child rearing conducted by Cabinet Office of Japan (2010) is used.

$\tau_{r, t}, \tau_{w, t}, \tau_{p, t}$, and $\tau_{c, t}$ are the interest income tax rate, the wage income tax rate, the public pension contribution rate, and the consumption tax rate, respectively. $\tau_{e, s, t}$ is the contri-

\footnotetext{
${ }^{12}$ The average number of children the representative household in each cohort has is calculated by the ratio of the total number in the cohort of age 0 to the total number in the cohort of age 28 in each period.

${ }^{13}$ Precisely speaking, the household keeps rearing its own child until the end of age 19 of its own child.

${ }^{14}$ The Cabinet Office of Japan conducted an analysis on the financial cost of child rearing based on a questionnaire by internet (2009), and this paper calculates the value of $d_{x, t}$ based on the questionnaire analysis.
} 
bution rate to the long-term care insurance (LTCI), which is applied to the representative household while it is working in age $s$ at time $t^{15}$. After retirement, the representative household still has to contribute to the LTCI. The fixed amount of contributions is denoted by $I C_{s, t}$ in age $s$ at time $t$. Note that an individual starts to contribute to the LTCI once she becomes age 40 in Japan. Between age 40 and 64, all individuals belong to the second group (age group between 40 and 64), and the amount of their contributions depends on their earnings. Their contribution rate is given by $\tau_{e, s, t}$. Once an individual becomes age 65 , then she is transferred to the first group (age group of 65 and over), in which she still has to contribute to the LTCI, but the amount of contributions is fixed by $I C_{s, t}$. This paper takes into account such a realistic aspect of the LTCI, and the contribution rate for the second group (age group between 40 and 64) and the fixed amount of contributions for the first group (age group of 65 and over) are both calculated based on A Summary of the Long-term Care Insurance by the Ministry of Health, Labor and Welfare (MHLW; 2017). $L T_{s, t}$ is the total cost of obtaining services through the LTCI, and the $\theta_{t}$ is the co-payment rate at time t. $L T_{s, t}$ is calculated based on Survey of Long-term Care Benefit Expenditure (SLCBE) of year 2014, and $L T_{s, t}$ is assumed to be age-dependent, but time invariant. $\theta_{t}$ is assumed to be 0.1 to reflect the current rate.

Labor efficiency of four different workers is obtained from the data. In this paper, Basic Survey of Wage Structure (BSWS) of year 2011 and Labor Force Survey (LFS) of year 2012 are both used to specify the efficiency profile of each worker over time. The weight for efficiency of the household in age $s, e_{s}$, was calculated from these two data sets. In the simulation section, efficiency of male non-regular workers in age 20 - 24 is used to normalize efficiency of other workers in different age. Note also that the wage rate, $w_{t}$, the household faces is determined in the competitive labor market, and the total wage income of the household is the weighted average wage income of four different workers. The wage profiles

\footnotetext{
${ }^{15}$ Precisely speaking, although the retirement age is assumed to be fixed at age 65 , the positive rate of $\tau_{e, s, t}$ is applied up to age 64 , and it becomes zero when the representative household becomes age 65 . When the household becomes age 65, it starts paying the fixed amount of contributions.
} 
of four different workers are obtained from the above two data sets. The time spent on child rearing and elderly care is also differentiated among four different types of workers; male regular, male non-regular, female regular, and female non-regular workers.

Thus, the total labor supply by the representative household in age $s$ at time $t$ is such that:

$$
\begin{aligned}
e_{s}\left(1-l_{s, t}-l c_{s, t}-l e_{s, t}\right) & =\nu_{m, f t}^{s} e_{m, f t}^{s}\left(1-l_{s, t}-l c_{s, t, m, f t}-l e_{s, t, m, f t}\right) \\
& +\nu_{f e, f t}^{s} e_{f e, f t}^{s}\left(1-l_{s, t}-l c_{s, t, f e, f t}-l e_{s, t, f e, f t}\right) \\
& +\nu_{m, n f}^{s} e_{m, n f}^{s}\left(1-l_{s, t}-l c_{s, t, m, n t}-l e_{s, t, m, n t}\right) \\
& +\nu_{f e, n f}^{s} e_{f e, n t}^{s}\left(1-l_{s, t}-l c_{s, t, f e, n t}-l e_{s, t, f e, n t}\right),
\end{aligned}
$$

where $m, f e, f t$, and $n t$ denote male, female, regular contract, and non-regular contract, respectively. Thus, $e_{k, n}^{s}$ denotes labor efficiency of gender $k$ of contract type of $n$ in age $s$. $v_{k, n}^{s}$ denotes the weight of gender $k$ of contract type of $n$ in age $s$ in efficiency of the household. Note that both $e_{k, n}^{s}$ and $v_{k, n}^{s}$ are also calculated from LFS (2012) and BSWS (2011). $l c_{s, t, k, n}$ and $l e_{s, t, k, n}$ are time spent on child rearing and elderly care by gender $k$ of contract type of $n$ in age $s$ at time $t$, respectively. $l c_{s, t, k, n}$ and $l e_{s, t, k, n}$ are calculated from Survey on Time Use and Leisure Activities (STULA) of year 2012. All four different workers in the representative household retire at the end of their age of 65 , and they never come back to the labor market after their retirement.

$b_{s, t}$ is the amount of public pension benefits in age $s$ at time $t^{16} . w_{t}$ and $r_{t}$ are the wage rate per the efficiency unit and the interest rate, respectively. Public pension benefits are given by

$$
b_{t}=\left\{\begin{array}{c}
\epsilon_{t}\left(H_{t}+\bar{H}_{t}\right) ; \quad s \geq R H \\
0 ; \quad s,<R H
\end{array}\right\},
$$

where $R H$ is the retirement age of 65 , and fixed through this paper. This implies that

\footnotetext{
${ }^{16} \mathrm{~A}$ simplified assumption on the pension benefits is made in this paper. For more detailed studies, see, for instance, Yamada (2011) and İmrohoroğlu et al (2016).
} 
the representative household optimally chooses labor supply in intensive margin but not in extensive margin. Public pension benefits are taxed to reflect reality. $\epsilon_{t}$ is the replacement rate $^{17} . \bar{H}_{t}$ and $H_{t}$ denote the fixed amount of basic pension benefits and earning related benefits, respectively, and $H_{t}$ is given by:

$$
H_{t}=\frac{1}{R H} \sum_{s=20}^{R H} w_{t} e_{s}\left(1-l_{s, t}-l c_{s, t}-l e_{s, t}\right) .
$$

It is assumed that the representative household maximizes (1) with respect to $c_{s, t}$ and $l_{s, t}$ subject to (3), and the first order conditions yield the following optimal equations:

$$
\begin{aligned}
u^{\prime}\left(c_{s, t}, l_{s, t}\right) u\left(c_{s, t}, l_{s, t}\right)^{-\rho} & =\frac{q_{s+1, g}\left[1+\left(1-\tau_{r, t+1}\right) r_{t+1}\right]}{1+\delta} \frac{1+\tau_{c, t}}{1+\tau_{c, t+1}} \\
& \times u^{\prime}\left(c_{s+1, t+1}, l_{s+1, t+1}\right) u\left(c_{s+1, t+1}, l_{s+1, t+1}\right)^{-\rho}, \\
l_{s, t} & =\left[\frac{\kappa\left(1+\tau_{c, t}\right)}{\left(1-\tau_{w, t}-\tau_{p, t}-\tau_{e, s, t}\right) w_{t} e_{s}}\right]^{\xi} c_{s, t},
\end{aligned}
$$

where

$$
u^{\prime}\left(c_{s, t}, l_{s, t}\right)=\frac{\partial\left(c_{s, t}, l_{s, t}\right)}{\partial c_{s, t}}
$$

\subsection{The Firm}

The firm is assumed to maximize its profits, taking the wage rate and the interest rate as given. The wage rate and the interest rate are determined in perfectly competitive factor markets in equilibrium in each period. The aggregate private production function is assumed to be Cobb- Douglas such that

$$
Y_{t}=\Omega_{t} L_{t}^{\alpha} K_{t}^{1-\alpha}
$$

\footnotetext{
${ }^{17}$ There are several definitions of the replacement rate of the public pension scheme. See İmrohoroğlu et al (2016) in detail. This paper uses the Japanese official definition of the replacement rate, which is defined as the ratio of pension benefits, which a typical household of a 65 years old husband of category 2 and a wife only with the basic fixed amount of pension benefits receives, to average disposal earnings of category 2 male workres. The replacement rate based on this definition is currently just above $60 \%$.
} 
where $Y_{t}, K_{t}$ denote aggregate output, and capital at time $t . L_{t}$ is total labor demand measured in the efficiency unit. $\Omega_{t}$ is technology of production of the private sector. The fully competitive assumption of factor markets yields:

$$
\begin{aligned}
w_{t} & =\alpha \frac{Y_{t}}{L_{t}}, \\
r_{t} & =(1-\alpha) \frac{Y_{t}}{K_{t}}-\varphi,
\end{aligned}
$$

where $\varphi$ is the depreciation rate.

\subsection{The Government}

The government sector consists of a long-term care insurance account, a general account, and a public pension account. The government issues government bonds, and accumulates the public pension fund. Each account is separately considered as follows.

\subsubsection{Long-term Care Insurance (LTCI) Account}

The budget constraint of the long-term care insurance (LTCI) is given by:

$$
T L T_{t}=F I C_{t}+T I C_{t}+O I C_{t}+E_{t}
$$

where $T L T_{t}$ is the total expenditure in the account at time $t$, and it is given by:

$$
T L T_{t}=\sum_{s=R H-1}^{99}\left(1-\theta_{t}\right) L T_{s, t} P O P_{s, t}
$$

$E_{t}$ is the amount of transfers from the general account to the long-term care insurance account at time $t . L T_{s, t}$ is the total cost through the LTCI, and the $\theta_{t}$ is the co-payment rate imposed on the representative household at time $t . P O P_{s, t}$ denotes the total population of age $s$ at time $t$. 
$F I C_{t}$ and $T I C_{t}$, are aggregated revenues contributed by each household at time $t$, which are such that:

$$
\begin{aligned}
F I C_{t} & =\sum_{s=40}^{R H-1} \tau_{e, s, t} w_{t} e_{s}\left(1-l_{s, t}-l c_{s, t}-l e_{s, t}\right) P O P_{s, t} \\
T I C_{t} & =\tau_{e, R H-1, t} w_{t} e_{R H-1}\left(1-l_{R H-1, t}-l c_{R H-1, t}-l e_{R H-1, t}\right) P O P_{R H-1, t}+\sum_{s=R H}^{99} I C_{s, t} P O P_{s, t} .
\end{aligned}
$$

Note that $F I C_{t}$ and $T I C_{t}$ are the total contributions by the household which belongs to the first group between age 40 and 64, and to the second group between age 65 and over, respectively. The household has to pay a part of the total cost as a co-payment when it receives services through the long-term care insurance. The current co-payment rate, $\theta$, is $10 \% . O I C_{t}$ is the total amount the household pays by itself when it receives services through the long-term care insurance at time $t$, which is given by:

$$
O I C_{t}=\sum_{s=R H-1}^{99} \theta_{t} L T_{s, t} P O P_{s, t} .
$$

In order to reflect reality, $\tau_{e, s, t}$ and $I C_{s, t}$ are both endogenously calculated to satisfy (6) in the following simulations.

\subsubsection{General Account}

The budget constraint of the general account is such that:

$$
D_{t+1}-D_{t}=A G_{t}+r_{t} D_{t}+P_{t}+E_{t}+C H_{t}-R_{t}
$$

where $D_{t}$ denotes the amount of outstanding government debts at time $t . A G_{t}$ is the total government expenditure. $P_{t}$ is the amount of transfers from the general account to the public pension account at time $t$. $C H_{t}$ denotes the total amount of a child allowance given to each household. A child allowance is assumed to be given to the household while it is between 
age 28 and 43. Thus,

$$
C H_{t}=\sum_{s=28}^{43} d_{s, t} P O P_{s, t},
$$

where $d_{s, t}$ denotes the amount of a child allowance per household. $R_{t}$ is the total tax revenue, which is given by:

$$
R_{t}=\tau_{w, t}\left(w_{t} L_{t}+A B_{t}\right)+\tau_{r, t} A S_{t}+\tau_{c, t} A C_{t}+\tau_{q, t} B Q_{t}
$$

where $^{18}$

$$
\begin{aligned}
L_{t} & =\sum_{s=0}^{R H} e_{s}\left(1-l_{s, t}-l c_{s, t}-l e_{s, t}\right) P O P_{s, t} \\
& =\sum_{s=0}^{R H}\left[\nu_{m, f t}^{s} e_{m, f t}^{s}+\nu_{f e, f t}^{s} e_{f e, f t}^{s}+\nu_{m, n f}^{s} e_{m, n f}^{s}+\nu_{f e, n f}^{s} e_{f e, n t}^{s}\right]\left(1-l_{s, t}-l c_{s, t}-l e_{s, t}\right) P O P_{s, t} .
\end{aligned}
$$

The aggregated values of $A B_{t}, A S_{t}, A C_{t}$, and $B Q_{t}$ are given by:

$$
\begin{aligned}
A B_{t} & =\sum_{s=R H}^{99} b_{s, t} \text { POP }_{s, t} \\
A S_{t} & =\sum_{s=20}^{99} a_{s, t} P O P_{s, t} \\
A C_{t} & =\sum_{s=20}^{99} c_{s, t} P O P_{s, t} \\
B Q_{t} & =\sum_{s=20}^{99} b q_{s, t} \text { POP }_{s, t} .
\end{aligned}
$$

\footnotetext{
${ }^{18}$ The labor market is assumed to be fully competitive, and (12) is also interpretted as an equilibrium condition of the labor market
} 


\subsubsection{Public Pension Account}

On the public pension account, the budget constraint is such that:

$$
F_{t+1}-F_{t}=r_{t} F_{t}+P_{t}+C P_{t}-A B_{t}
$$

where $F_{t}$ denotes the accumulated pension fund at time $t . C P_{t}$ is the total amount of contributions collected at time $t$, which is given by:

$$
C P_{t}=\sum_{s=20}^{R H} \tau_{p, t} w_{t} e_{s}\left(1-l_{s, t}-l c_{s, t}-l e_{s, t}\right) P O P_{s, t}
$$

\subsection{Competitive Equilibrium}

For a given sequence of all demographic parameters, $\left\{P O P_{t}, P_{t-g}\right\}_{t=0}^{\infty}$, a given sequence of all government policies, $\left\{D_{t}, F_{t}, d_{s, t}, \tau_{w, t}, \tau_{r, t}, \tau_{c, t}, \tau_{q, t}, \tau_{p, t}, \tau_{e, s, t}, \tau_{e, R H-1, t}, \theta_{t}, b_{t}, I C_{s, t}, \epsilon_{t}, \bar{H}_{t}\right\}_{t=0}^{\infty}$, and a given sequence of the financial cost of child rearing as well as of elderly care services, $\left\{h_{s, t}, L T_{s, t}\right\}_{t=0}^{\infty}$, the perfect foresight competitive equilibrium is defined as the sequence of $\left\{r_{t}, w_{t}\right\}_{t=0}^{\infty}$, which satisfies the following conditions:

1. The optimal conditions for the representative household, (5) and (6), are satisfied for all generations in each period with the non-ponzi condition.

2. The optimal conditions for the firm, (8) and (9), are satisfied in each period.

3. Three budget constraints for the government, (11), (13), and (10), are satisfied in each period.

4. The capital market equilibrium condition is satisfied in each period such that:

$$
A S_{t}+F_{t}=K_{t}+D_{t} .
$$

5. The goods market equilibrium condition is satisfied in each period such that: 


$$
Y_{t}=A C_{t}+K_{t+1}-(1-\varphi) K_{t}+A G_{t}
$$

6. The sequence of the consumption tax rate, $\left\{\tau_{c, t}\right\}$, is endogenously determined to satisfy (11) from year 2019.

7. The sequence of the contribution rate of the public pension scheme, $\left\{\tau_{p, t}\right\}$, is endogenously determined to satisfy (13) until year 2017.

8. The sequence of the replacement rate of the public pension scheme, $\left\{\epsilon_{t}\right\}$, is endogenously determined to satisfy (13) from year 2018.

9. The sequence of the revenue instruments of the LTCI, $\left\{\tau_{e, s, t}, \tau_{e, R H-1, t}, I C_{s, t}\right\}$, is endogenously determined to satisfy (10) in each period.

\section{Calibration}

\subsection{Demographics}

The assumption on the demographics is a key factor, and all available data should be used as much as possible. From year 2016 to year 2115, the latest population projection of year 2017 by the IPSS is used for age 0 to 100. Since the IPSS produces a reference estimate from year 2066 to year 2115 as well as the usual estimate till 2065, such a reference estimate with the medium variant assumption for both fertility and mortality rates is also used for the future demographics. From year 2116, the same distribution as that of year 2115 is assumed for another 100 years. As Figure 1 shows, the Japanese economy converges to a new steady state with the high dependency ratio under this assumption, but this could be most done to make this study as close to reality as possible. In the growing literature all studies assume that the Japanese economy converges to a new steady state with a low dependency ratio after experiencing its very high ratio at peak. However, based on the latest population projection of year 2017, a new steady state is described with a quite high dependency ratio. The IPSS 
estimates that the Japanese economy remains in a steady state with a high dependency ratio. Since the latest population projection of year 2017 by the IPSS only shows the reliable future demographics of a graying Japan, this paper uses the entire estimates by the IPSS until year 2115, rather than imposing any assumption to converge to a new steady state with a low dependency ratio in the next 100 years.

Regarding the past demographic structure, the actual data from year 1920 to year 2015 is used. This paper tries to use the oldest data of the past population structure as much as possible. Since there are many overlapping generations alive even in a initial state, the past demographics directly affect the initial state. This paper tries to minimize the impact of adhoc assumptions on the initial demographic structure on model specification in a benchmark model.

Parameter values are set to reproduce the values of key variables in the model as close to real values in year 2012 as possible in the following benchmark. some available parameter values in the literature are used. Although parameter values are calibrated under such an assumption, it is not assumed that year 2012 is an initial steady state in this paper. In reality, year 2012 is also on the transition of the demographic structure. This paper, instead, tries to use the past data as much as possible, in order to minimize the impact caused by the ad-hoc assumption on the past demographics. Note that in year 2012 there are still many old generations born in the past, and their behavior affects all future policies. The distortionary impact of the population structure should be minimized. Since the oldest available data starts from year $1920^{19}$, the demographic structure before year 1920 is assumed to have the same distribution as that of year 1920 .

As Auerback and Kotlikoff (1987) and De Nardi et al (1999) pointed out, the impact of policy changes is quite different among different generations, and the impact on an economy on the transition matters in a computable general equilibrium model. Instead of assuming

\footnotetext{
${ }^{19}$ The data of age 85 and over from year 1920 to 1946 was calculated based on the actual survival rate of age 85 and over between year 1947 and 1948. The data of all ages from year 1941 to 1943 are missing, and missing data was recursively calculated based on the survival rates of all ages between year 1947 and 1948 with the data of year 1944.
} 
an initial steady state, this paper explores the impact of several policies in a graying Japan on transition. Since all parameter values of the total population and the survival rate are calculated by using the actual and projected data, the demographics in the model can perfectly capture the actual and projected demographic structure with the assumption of no uncertainty in the aggregated values.

\subsection{Preference and Production}

Key parameter values in (1) and (2) have been carefully calibrated in order for the model values of key variables in the benchmark model to become close to those of year 2012. The benchmark model is discussed again in Section 5.4. The detailed values of parameters are given in Table 1.

On the values of tax rates and parameter values in production, available values from Hayashi and Prescott (2002) as well as Hansen and İmrohoroğlu (2016) are used. See in Table 1. On the value of technological progress $\left(\Omega_{t}\right)$, as pointed out by Ihori et al (2006), all simulation results are quite sensitive to the value. As will be discussed in Section 5.4, this paper tries to follow several assumptions given in the actual government strategy. In such official strategy documents, the future economic growth rates are given as targeted values. However, the economic growth rate is endogenously calculated in this paper, and it cannot be given exogenously. Thus, this paper exogenously gives the value of $\Omega_{t}$ so that the endogenously calculated rate of economic growth becomes close to the exogenous value given in the official documents made by the Japanese government. The model values of economic growth calculated endogenously in the benchmark model will be shown in Section 5.4.

\subsection{Government}

The assumption on the future government policy is another key factor. The Japanese government has been trying to stimulate the Japanese economy based on the so-called growth strategy, of which the main policy of Abenomics consists. In order to accomplish the growth 
strategy, the government documented concrete figures ${ }^{20}$ of several key variables such as the future primary balance and economic growth as targeted figures. Miyazawa and Yamada (2015) examined the growth strategy of Abenomics within the framework of Auerback and Kotlikoff (1987), and they concluded that the growth strategy seems difficult to be achieved even under very optimistic assumptions made in one of the official documents, Economic and Fiscal Projections for Medium to Long-term Analysis (July 2014). This paper uses several assumptions made in the latest version of Economic and Fiscal Projections for Medium to Long-term Analysis (EFPMLA: January 2016) to specify the future government policy, and expands Miyazawa and Yamada (2015) by separately introducing the government accounts in a more realistic way.

In Economic and Fiscal Projections for Medium to Long-term Analysis (EFPMLA: January 2016), there are two assumptions on the future economic environment up to year 2024; a recovery case and a baseline case. Figure 2-1 shows the different assumption on the future primary balance between two cases. Figure 2-2 also shows the different assumption on the future government deficits between two cases. In both figures the actual data is used until year 2014. As both figures show, the assumptions on the future values of the recovery case seems quite optimistic in comparison with the past trend. Furthermore, the future economic growth rate in the recovery case is assumed to be more than $3 \%$ in the nominal term and more than $2 \%$ in the real term ${ }^{21}$. Figure 2-3 shows the past trend and the different future economic growth rates given in two cases, and optimistic assumptions in the recovery case can be found. Based on this observation, this paper follows assumptions made in the baseline case of Economic and Fiscal Projections for Medium to Long-term Analysis (EFPMLA: January 2016) as follows.

\footnotetext{
${ }^{20}$ Several official documents have been made. This paper follows several assumptions made by the Cabinet Office of Japan (Economic and Fiscal Projection for Medium to Long-term Analysis (January 2016)).

${ }^{21}$ In the baseline case, the fture economic growth rate is assumed to be $1.5 \%$ in the nominal term and less than $1 \%$ in the real term.
} 


\subsubsection{Long-term Care Insurance (LTCI) Account}

The public long-term care insurance (LTCI) for the elderly was introduced in year 2000. The expenditures basically depend on the demographic structure and population aging, and the expenditures seem exogenous to the scheme with its unchanged structure. In fact, in the actual scheme of the LTCI, the revenue is endogenously calculated to balance the budget where expenditures are exogenously given. This paper assumes the exogenous expenditures and also endogenously calculates the fixed amount and the rate of contributions paid by the insured. Figure 3-1 shows the future expenditures in the LTCI based on the assumption that the age-dependent cost is time-invariant. The values in Figure 3-1 are calculated only by reflecting population aging ${ }^{22}$, and these values are given exogenously in this paper.

On the revenue side, a $10 \%$ of the total cost is paid by the insured as co-payments who receive services through the scheme. A half of the remaining cost (90\% of the total cost) is covered by transfers from the general account $\left(E_{t}\right)$. Another half of the remaining cost is paid by the insured. A $28 \%$ and a $22 \%$ of the remaining cost are currently paid by people belonging to the second group, and the first group, respectively. Note that the scheme is compulsory so that people between age 40 and 64 have to belong to the second group, and people of age 65 and over have to belong to the first group.

The current ratios of the distribution of the cost between the first group (age 65 and over) and the second group (ages between 40 and 64) are $22 \%$ and 28\%, respectively. While the total ratio paid by the insured remains at $50 \%(=22 \%+28 \%)$ of the $90 \%$ of the total cost, the ratios between two groups will change according to the future demographic structure. The MHLW has announced that the ratios will be modified every 3 years, and indeed the actual ratios have been changed since its launch in year 2000. Table 2 shows the actual ratios in the past as well as the future calculated ratios based on the guideline

\footnotetext{
${ }^{22}$ The age specific cost in the LTCI is used for Figure 2. The age specific cost is calculated based on Survey of Long-term Care Benefit Expenditure (SLCBE) of year 2014. Based on the assumption that the age specific cost does not change over time, Figure 2 shows the future cost of the LTCI by reflecting the future change in the demographics of Japan.
} 
made by the MHLW. This paper endogenously calculates the contribution rate $\left(\tau_{e, s, t}\right)$ for the second group and the fixed amount of contributions $\left(I C_{s, t}\right)$ for the first group to satisfy (6), based on the given ratios in Table 2 .

Note also that a $50 \%$ of the remaining cost is paid by the central and local governments in the actual LTCI. Since the future total expenditures of the LTCI change according to population aging, the total amount of transfers from the general account to the LTCI account $\left(E_{t}\right)$ also changes.

\subsubsection{General Account}

The future government expenditures and future deficits are both exogenously given. The future government expenditures are assumed to increase according to population aging based on the latest Population Projection of year 2017 by the IPSS. According to the past increasing trend of social security benefits, the future government expenditures are assumed to gradually increase in Figure 3-2, which shows the past trend and the future assumed values. The actual value is used until year 2014 .

On the future deficits, the assumption made in the baseline case in EFPMLA is used. Figure 3-3 shows the future scenario of the ratio of outstanding government debts to GDP. The actual values of government expenditures, deficits, and GDP are used until year 2014.

The consumption tax rate is assumed to be endogenously calculated after year 2019 in order to satisfy (11) with the future given values of government expenditures and deficits. In order to reflect reality, the consumption tax rate exogenously remains at $8 \%$ until year 2018, while the wage income tax rate is endogenously calculated until 2018 to satisfy $(11)^{23}$. All other tax rates are exogenously given shown in Table 1, and the consumption tax is only used to measure to the extent how much population aging affects the general account in the

\footnotetext{
${ }^{23}$ The exogenously given values of the consumption tax rate in all simuations are $0 \%, 3 \%, 5 \%$, and $8 \%$ for before year 1989, between 1989 and 1997, between 1997 and 2014, and between 2014 and 2018 , respectively. The wage income tax rate is given exogenously after year 2018 at the same value of that of year 2018.
} 
government budget ${ }^{24}$.

\subsubsection{Public Pension Account}

According to the recent decision by the Ministry of Health, Labor and Welfare (MHLW), the decreasing trend of the GDP ratio of accumulated public pension fund has already started since year 2003 in reality. Then, by following the actual plan of decreasing the fund in the next 100 years to the minimum level, the public pension fund is assumed to keep decreasing down to the level at which the annual amount of total benefits can be paid in year 2115 . Figure 3-4 shows the actual past trend and the future values given in the following numerical analysis. Until year 2014, the actual values are used in the figure.

A half of the total amount of basic pension benefits is transferred annually from the general account, which is $P_{t}$ in (11) and (13). Until year 2003 the transfer rate, defined as the ratio of transfers from the general account to the total basic pension benefits, was one-third, and it was gradually increased to a half from year 2004 to year 2009 in reality. This paper incorporates this fact.

The contribution rate $\left(\tau_{p, t}\right)$ and the replacement rate $\left(\epsilon_{t}\right)$ are endogenously calculated in order to satisfy (13) under the assumption of values in Figure 3-4. In order to reflect the actual policy change, the contribution rate is endogenously calculated until year 2017 to satisfy the budget constraint of the public pension account with the fixed rate of the replacement. Until year 2017 the contribution rate is an endogenous policy instrument to satisfy (13). From year 2018, as the Ministry of Health, Labour and Welfare of Japan (MHLW) announced, the contribution rate is exogenously given at $18.3 \%$, and the replacement rate becomes a new policy instrument to satisfy (13), so that the replacement rate is endogenously calculated from year 2018. The MHLW announced that the replacement rate will be reduced gradually to $50 \sim 51 \%$ in the future, and it is reported that the replacement rate in

\footnotetext{
${ }^{24}$ As pointed by Kitao (2015a), the wage income tax is more distortinary to labor supply than the consumption tax, and thus a more welfare loss is generated by the wage income tax. This paper only uses the consumption tax to finance the future government policy.
} 
year 2009 was $62.3 \%^{25}$. Thus in this paper the exogenous replacement rate is assumed to be fixed at $62.3 \%$ until year 2017, while the contribution rate is endogenously calculated until year 2017 in order to satisfy the budget constraint of (13). From year 2018 the replacement rate is endogenously calculated, while the contribution rate is exogenously fixed at $18.3 \%$ afterwards.

\subsection{Benchmark}

While this paper does not assume any initial steady state, year 2012 is assumed to be a benchmark year. This implies that parameter values have been given for the values of key variables calculated within the model for year 2012 to be as close to actual values in year 2012 as possible. Table 3 shows the comparison of values of key variables between actual and model values in year 2012. Figures 4-1 and 4-2 show model prediction of the primary balance and the real GDP growth rate, respectively. Note that in both figures future values are obtained from the baseline case in Economic and Fiscal Projections for Medium to Longterm Analysis (EFPMLA: January 2016). Note also that the annual economic growth rate assumed in the baseline case in Economic and Fiscal Projections for Medium to Long-term Analysis (EFPMLA: January 2016) is 0.8 \% from year 2019 to 2024.

Figure 4-3 shows the endogenously calculated value of technological progress denoted by $\Omega$ in (7). Note that the value given in Figure $4-3$ resulted in the model value of the GDP growth rate given in Figure 4-2. Since the future labor force is expected to decrease, technology has to keep increasing in order to maintain GDP at a certain level. Since the total population is expected to decrease in the future, keeping annual economic growth rate of GDP at $0.8 \%$ implies a constant increase in $\Omega$. This also implies that the growth rate of GDP per capita is further higher with a shrinking population.

In the following numerical experiments, technological progress is assumed to increase

\footnotetext{
${ }^{25}$ Note that this is the offical replacement rate. See Kitao (2015a) for different definitions of the replacement rate. The official replacement rate used here is different from the definition of the replacement rate used in Kitao (2015a, 2015b, and 2017).
} 
based on the value given in Figure 4-3, in order to follow the assumption on the future environment given in the baseline case in Economic and Fiscal Projections for Medium to Long-term Analysis (EFPMLA: January 2016).

\section{$6 \quad$ Numerical Results}

The purpose of this paper is to explore the impact of population aging on the LTCI in a graying Japan within the framework of Auerback and Kotlikoff (1987), with the assumption on the future environment given in the baseline case of Economic and Fiscal Projections for Medium to Long-term Analysis (EFPMLA: January 2016).

\subsection{Impact of Population Aging}

Table 4 shows the impact of population aging on the Japanese LTCI in the benchmark. Note that the distribution of the cost between the first and second groups is adjusted according to Table 2 in the benchmark. The increasing trend rises from population aging, and both groups have to pay more cost. In the next about forty years, the burdens on the first and second groups become more than 1.7 times (5,514 yen to 9,457 yen) and more than 2.7 times $(2.07 \%$ to $5.68 \%)$ as much, respectively. Note that more cost will be distributed to the first group in the future by reflecting the change in the future demographics according to Table

2. However surprisingly, more distribution of the cost to the first group does not help to reduce increasing burdens on the second group. This is because the relative size of cohorts between age 40 and 64 to the size of the first group of age 65 and over drastically decreases, so that the cohorts between age 40 and 64 further have to pay the increasing cost caused by population aging. The cohorts which basically obtain elderly care services through the LTCI belong to the first group. This implies that the second group further has to support the first group through the LTCI in a graying Japan. The intergenerational transfer mechanism exists not only in the current public pension scheme, but also in the LTCI in a graying Japan. 


\subsection{Policy Options}

Population aging results in more burdens on both age groups. In particular, population aging leaves relatively more burdens on the second group of age 40 to 64 through the intergenerational transfer mechanism of the LTCI.

In this section, the impacts of three possible policy options intended to reduce burdens on the second group (age 40 to 64 ) are explored; an increase in co-payments by the elderly who obtains elderly care services through the LTCI, a wider coverage of contributing cohorts, and a change in the cost distribution between the public sector and the insured.

In the following experiments, a policy change occurs in year 2018 and it continues onwards.

\subsubsection{Policy 1: Higher Co-payments}

Currently the elderly has to co-pay a $10 \%$ of the total cost when the elderly uses elderly care services through the LTCI. The impact of an increase in the co-payment rate is explored. In this experiment, the co-payment rate increases from 10\%, the current rate, to $20 \%$ as well 30 \%. Tables 5-1 and 5-2 show the impact on both the first and second groups. Table 5-2 shows the percentage changes from the benchmark level. Both Tables show that the reduction rate of burdens on the second group (age 40 to 64 ) is larger when the co-payment rate increases. For instance, if the co-payment rate increases from the current level of $10 \%$ to $30 \%$, then the burden on the second group is reduced gradually up to more than $12 \%$.

\subsubsection{Policy 2: Earlier Contributing Age}

A change in a coverage of contributing cohorts is examined in this experiment. Under the current scheme, all cohorts have to contribute to the scheme once they become age 40. In this option, a starting age to start contributing to the LTCI becomes earlier from the current age of 40 to 30 or 35 , so that all cohorts start contributing to the LTCI earlier. Indeed, this is one of the options which has currently been argued in actually ongoing discussions. Tables 
5-3 and 5-4 show the impact on the fixed amount of monthly contributions of the first group and also the contribution rate for the second group. Note that the elderly who obtains elderly care services through the LTCI usually belongs to the first group (age 65 and over) ${ }^{26}$. Thus, while a policy to increase the co-payment rate (Policy 1) induces more burdens on the first group through the increasing rate of co-payments, a policy to make a contributing age earlier (Policy 2) induces more burdens on the second group. Note also that Policy 2 tries to distribute the cost to more cohorts which belong to the second group. If the cost on the second group does not change, then Policy 2 intends to reduce the cost distribution to each cohort, and let more cohorts share the cost among all cohorts which belong to the second group. The contribution rate shown in Tables 5-3 and 5-4 is applied to each cohort, and this is the reason why the contribution rate decreases more than the case of Policy 1. In Policy 2, all cohorts start to contribute to the LTCI earlier and thus they contribute longer, but its contribution rate per year is lower.

\subsubsection{Policy 3: More Distribution of the Cost to Governments}

The last policy option changes the distribution of the cost between the public sector and the insured. Currently, the remaining total cost after paid by the insured as co-payments is equally distributed between the public sector $(50 \%)$ and the insured $(50 \%)^{27}$. In this last option, the equal distribution is modified. The change in the cost distribution between the public sector and the insured appears in (10) and (11), and more distribution of the cost to the public sector implies an increase in $E_{t}$ in (10) and (11). Since the consumption tax rate is adjusted to satisfy (11), more distribution of the cost to the public sector also implies a higher consumption tax, so that not only cohorts belonging to either group but also all cohorts alive have to share the cost through an increase in the consumption tax rate in this

\footnotetext{
${ }^{26}$ The cohoorts between age 40 and 64 , which belong to the second group, can also obtain the services through the LTCI. However, this is an exceptional case.

${ }^{27} \mathrm{~A} 10 \%$ of the total cost is initially paid as co-payments by the elderly who used the services through the LTCI. Then the remaining total cost, which is a $90 \%$ of the initial total cost, is equally paid by the public sector as transfers by the local governments and by the insured. A $50 \%$ of the remaining cost is further devided between the insured of the first and secong groups according to populaiton aging.
} 
option. The cost is distributed to all cohorts alive through an increase in the consumption tax rate. In this counterfactual experiment, the ratio of the cost distributed to the public sector increases to $60 \%$ and $70 \%$ from the current ratio of $50 \%$. Tables 5-5 and 5-6 show the impact. Both Tables show that the burdens on both groups are substantially reduced. However, Table 5-7 shows to the extent how much the consumption tax rate should increase to finance more burdens on the general account from which more transfers are made to the LTCI account. If a $70 \%$ of the remaining cost is paid by the public sector, the consumption tax rate has to increase by more than $20 \%$ in the long-run.

\subsection{Impact on Welfare}

The three policy options have indeed been considered in actual on-going arguments for future reforms of the LTCI in a graying Japan. The impact of such policy options on the whole economy should be evaluated based on welfare. The impact on welfare of different cohorts is calculated based on consumption equivalence, which measures a percentage change in consumption to make the household indifferent between the benchmark and alternative three policy options. If the calculated value of consumption equivalence is greater than 1 , then the household prefers an alternative policy option. Figure 5-1 shows the welfare effect of each policy option. Except very old cohorts born before year 1947, all cohorts most prefer

policy 1 with the co-payment rate of $30 \%$, and more future cohorts prefer it more. Figure 5-1 shows that Policy 1 of an increase in co-payments is most preferable compared to Policy 2 and Policy 3. Figure 5-2 shows consumption equivalence of Policy 2 and Policy 3 only. Figure 5-2 is exactly the same as Figure 5-1 without the cases of Policy 1. Figure 5-2 shows that the second best policy option is Policy 3 with a shift of the cost to the public sector from $50 \%$ to $60 \%$. However, more distribution of the cost to the public sector is not necessarily preferable particularly by future cohorts. If the currently equal distribution of the cost is modified to the distribution of a $70 \%$ by the public sector and a $30 \%$ by the insured, then Policy 2 with an earlier contributing age of 35 is more preferable than Policy 3 . This is 
because more distribution of the cost to the public sector induces a much higher consumption tax rate, and such a policy is not preferable particularly among future cohorts. Figure 5-2 also shows that an earlier contributing age of age 30 is least preferable by all cohorts among all policy options. Policy 2 with an earlier contributing age of 30 substantially reduces the burdens on the second group per year, and this result implies that all cohorts do not prefer the policy in which all cohorts to start to contribute to the scheme too early and thus too long with lower burdens per year.

The results are summarized. An increase in co-payments is most preferable among all three options. This implies that all cohorts most prefer the case where they pay the cost by themselves when they need services through the LTCI, rather than the policy of longer duration of contribution (Policy 2) or the policy followed by a higher consumption tax (Policy 3). As the second best policy, almost all cohorts choose a policy of distribution of a $60 \%$ of the cost to the public sector with a relatively slight increase in a consumption tax. However, particularly future cohorts do not prefer a policy with too much distribution of the cost to the public sector, since such a policy is followed by a very high consumption tax. Finally, while an earlier starting age of contribution of age 35 is the third best policy option for future cohorts, a too early starting age of contribution of age 30 is least preferable among all policy options even for future cohorts.

\section{Concluding Remarks}

This paper examined the impact of population aging on the Japanese public long-term care insurance (LTCI) within a numerical dynamic general equilibrium model with multiple overlapping generations.

Numerical results show that in the next about forty years the burdens on the first and second groups become more than 1.7 times and more than 2.7 times as much, respectively. A relatively more increase in the burdens on the second group cannot be avoidable, even if 
adjustment of the cost distribution between both groups is made every three years in the future in accordance with the schedule by the MHLW. In counterfactual experiments, the impact of three possible policy options were also examined; an increase in co-payments by the elderly, a wider coverage of contributing cohorts, and a change in the cost distribution between the public sector and the insured. Then, an increase in co-payments was the most preferable option. Furthermore, while almost all cohorts prefer an earlier starting age of contribution to the current age of 40 due to the fact that an earlier starting age of contribution

reduces burdens every year, too early staring age of contribution, thus too long duration of contribution is not preferable. While a shift of the cost to the public sector from the insured is also preferable, a too much shift of the cost is not preferable, since a large shift of the cost to the public sector is followed by a drastic increase in the consumption tax. These results show that cohorts prefer to pay the cost by themselves when they obtain elderly care services through the LTCI, rather than sharing the cost through their life in very long duration of contribution to the LTCI, or paying the cost with a high consumption tax.

\section{References}

[1] Agenor, Pierre-Richard (2017), 'A computable overlapping generations model for gender and growth policy analysis,' Macroeconomic Dynamics, 21, 11-54

[2] Akimura, Seika (2016), 'A comparative analysis of long term estimation of the cost of the long-term care insurance: On the Ageing Report by EC,' KIER Discussion Paper Series No. 1604, Kyoto Institute of Economic Research, Kyoto University (in Japanese)

[3] Auerbach, A and L J Kotlikoff (1987), Dynamic Fiscal Policy, Cambridge University Press

[4] Auerbach, A, L J Kotlikoff, and J Skinner (1983), 'The efficiency gains from dynamic tax reform,' International Economic Review, Vol. 24, 81 - 100 
[5] Basu, Kaushik (2006), 'Gender and Say: A model of household behaviour with endogenously determined balance of power, Economic Journal, 116, 558-580

[6] Braun, R. Anton and Douglas H. Joines (2015), 'The implications of a graying Japan for government policy,' Journal of Economic Dynamics \& Control 57, 1-23

[7] De Nardi, M., S. İmrohoroğlu, and Thomas, J. Sargent (1999), 'Projected US Demographics and Social Security,' Review of Economic Dynamics, 2, 575-615

[8] European Commission (2015), The 2015 Ageing Report: Economic and budgetary projections for the 28 EU Member States (2013-2060), European Commission

[9] Hansen, Gary D. and Selahattin Imrohoroğlu (2016), 'Fiscal Reform and Government Debt in Japan: A Neoclassical Perspective,' Review of Economic Dynamics, 21, 201-224

[10] Hayashi, Fumio, and Edward C. Prescott (2002), 'The 1990s in Japan: A Lost Decade,' Review of Economics Dynamics, 5, 206-235

[11] Homma, Masaaki, Naosumi Atoda, Yasushi Iwamoto, and Fumio Ohtake (1987), 'Pension: Aging society and public pension scheme,' in Macroeconomic analysis of the Japanese economy, Hamada, K, A Horiuchi, and M Kuroda eds, Tokyo University Press, 149 - 175 (in Japanese)

[12] Ihori, T, R R Kato, M Kawade, and S Bessho (2006), 'Public Debt and Economic Growth in an Aging Japan,' Chapter 3, in Tackling Japan's Fiscal Challenges: Strategies to Cope with High Public Debt and Population Aging, Kaizuka K and A O Krueger eds., Palgrave

[13] Ihori, T, R R Kato, M Kawade, and S Bessho (2011), 'Health Insurance Reform and Economic Growth: Simulation Analysis in Japan,' Japan and the World Economy, $23(4), 227-239$ 
[14] İmrohoroğlu, Selahattin, and Nao Sudo (2010), 'Productivity and Fiscal Policy in Japan,' IMES, Bank of Japan, Discussion Paper No. 2010-E-23

[15] İmrohoroğlu, Selahattin, Sagiri Kitao, and Tomoaki Yamada (2016), 'Achieving Fiscal Balance in Japan,' International Economic Review, Vol. 57 (1)

[16] Kato, Ryuta Ray (2017), 'Does more female labor supply really save a graying Japan ?,' EMS-2017-04, Economics \& Management Series, Research Institute, International University of Japan

[17] Kitao, Sagiri (2015a), 'Fiscal cost of demographic transition in Japan,' Journal of Economic Dynamics \& Control, 54, 37-58

[18] Kitao, Sagiri (2015b), 'Pension reform and individual retirement accounts in Japan,' Journal of the Japanese and International Economies, 38, 111-126

[19] Kitao, Sagiri (2017), 'When do we start? Pension reform in ageing Japan,' The Japanese Economic Review, 68 (1), 26-47

[20] Mitchell, Olivia S., John Piggott, and Satoshi Shimizutani (2008), 'An empirical analysis of patterns in the Japanese long-term care insurance system,' The Geneva Papers, 33, 694-709

[21] Miyazawa, Kensuke, and Junji Yamada (2015), 'The growth strategy of Abenomics and fiscal consolidation, Journal of the Japanese and International Economies, 37, 82-99

[22] Ohwa, Mie, and Li-Mei Chen (2012), 'Balancing long-term care in Japan,' Journal of Gerontological Social Work, 55, 659-672

[23] Shimizutani, Satoshi (2014), 'The future of long-term care in Japan,' Asia-Pacific Review, 21(1), 88-119

[24] Shirasawa, Masakazu (2015), 'Current situation and issues of the long-term care insurance system in Japan,' Journal of Asian Public Policy, 8(2), 230-242 
[25] Tajika, Eiji, and Jun Kikuchi (2014), 'Aging of society and medical and long-term care expenditures- Testing the Red Herring Hypothesis in Japan,' Financial Review, 117 (1), 52-77, Ministry of Finance, Japan (in Japanese)

[26] Tanaka, Shuji (2016), 'A proposal for redesigning social security: Long-term care pension,' The Geneva Paper, 41, 98-117

[27] Ueda, Junji, Yasutaka Yoneta, and Isao Ohta (2014), 'A quantitative analysis for required adjustments for Japan's fiscal policy,' Financial Review, 117 (1), 1-22, Ministry of Finance, Japan (in Japanese)

[28] Yamada, Tetsuji, Chia-Ching Chen, Tadashi Yamada, Marianne Fahs, and Tetsuo Fukawa (2006), 'Behavioral analysis of the choice of community-based formal home care, informal home care and nursing home care in Japan,' The Geneva Papers, 31, $600-632$

[29] Yamada, Tomoaki (2011), 'A politically feasible social security reform with a two-tier structure,' Journal of the Japanese and International Economies, 25, 199-224 


\section{Figure 1: Dependency Ratio}

\section{Dependency Ratio}

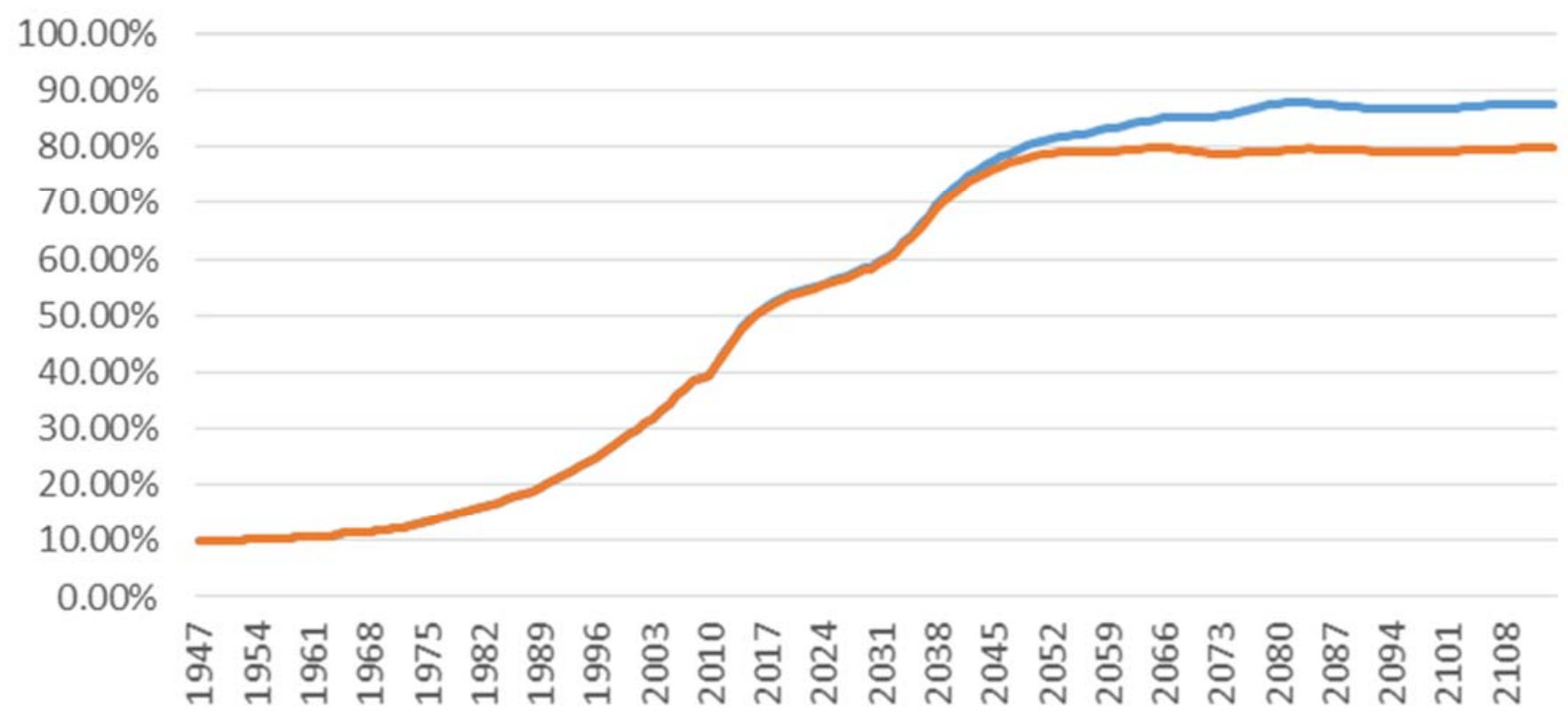

- Projection in year 2012 Projection in year 2017

Data: the actual data from Statistics Bureau, Ministry of Internal Affairs and Communications, and the future projections from the National Institute of Population and Social Security Research (IPSS) 
Table 1: Parameters

\begin{tabular}{cll}
\hline \hline Parameter & \multicolumn{1}{c}{ Description } & \multicolumn{1}{c}{ Value/Source } \\
\hline \hline$P_{s}$ & Survival rate & IPSS(2017) \\
$\delta$ & Subjective discount factor & $0.0286 /$ Kitao (2015a) \\
$\rho$ & Risk aversion & $3.0 /$ Kitao (2015a) \\
$\xi$ & Relative preference & 0.15 \\
$\kappa$ & Weight parameter for leisure & 0.00001 \\
$\tau_{r, t}$ & Interest income tax rate & $35.57 \% /$ Hansen and İmrohoroğlu (2016) \\
$\tau_{w, t}$ & Wage income tax rate* & $33.24 \% /$ Hansen and İmrohoroğlu (2016) \\
$\tau_{q, t}$ & Inheritance tax rate & $35.00 \%$ \\
$\alpha$ & Labor income share & $0.6217 /$ Hansen and İmrohoroğlu (2016) \\
$\varphi$ & Depreciation rate & $8.421 \% /$ Hansen and İmrohoroğlu (2016) \\
\hline
\end{tabular}

*) The wage income tax rate is endogenously calculated until year 2018, and it is exogenously given at this value from year 2019. 


\section{Figure 2-1: Primary Balance}

The GDP Ratio of Primary Balance

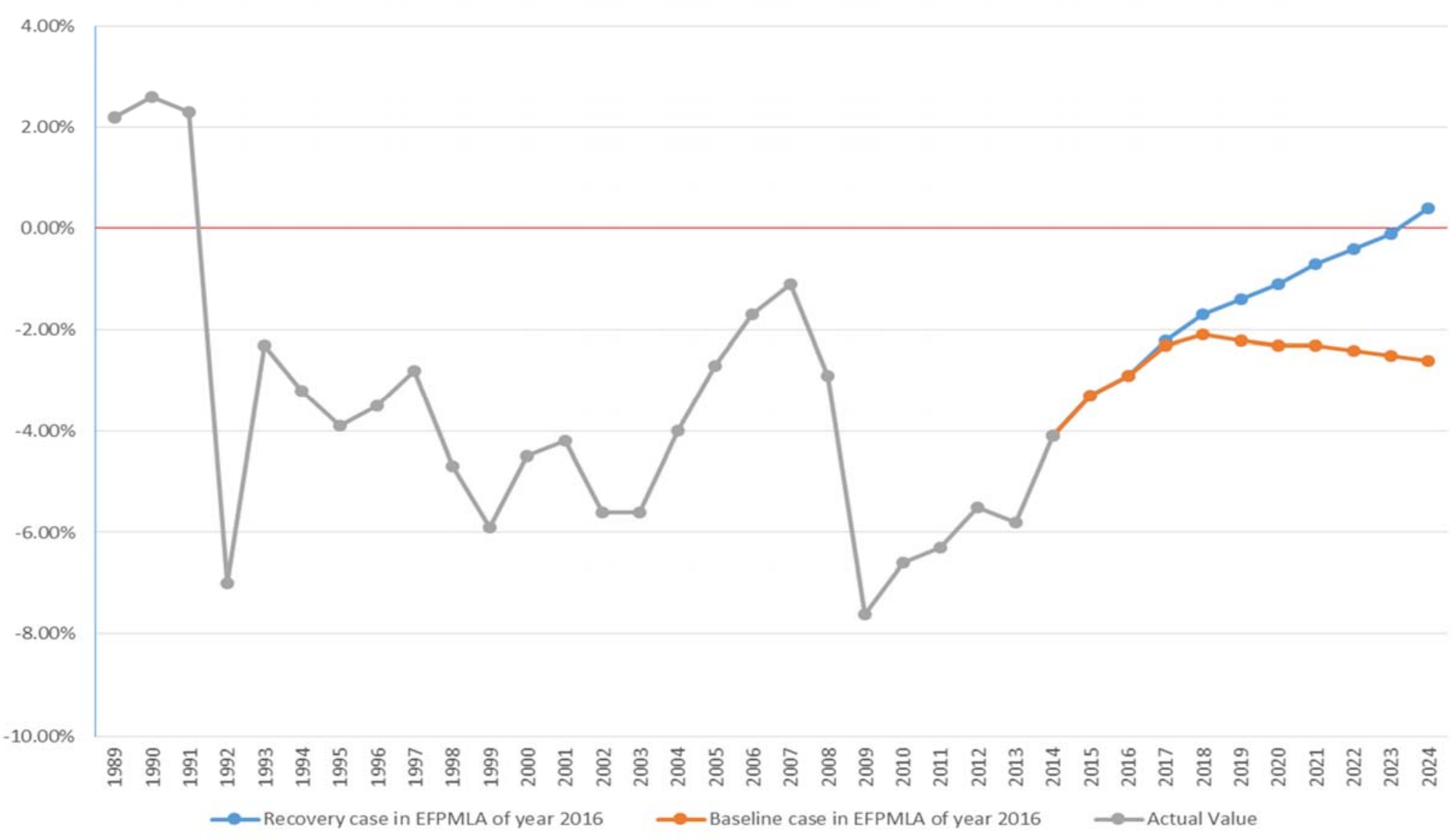


Figure 2-2: Government Deficits

The GDP Ratio of Outstanding Goverment Debts

$250.00 \%$

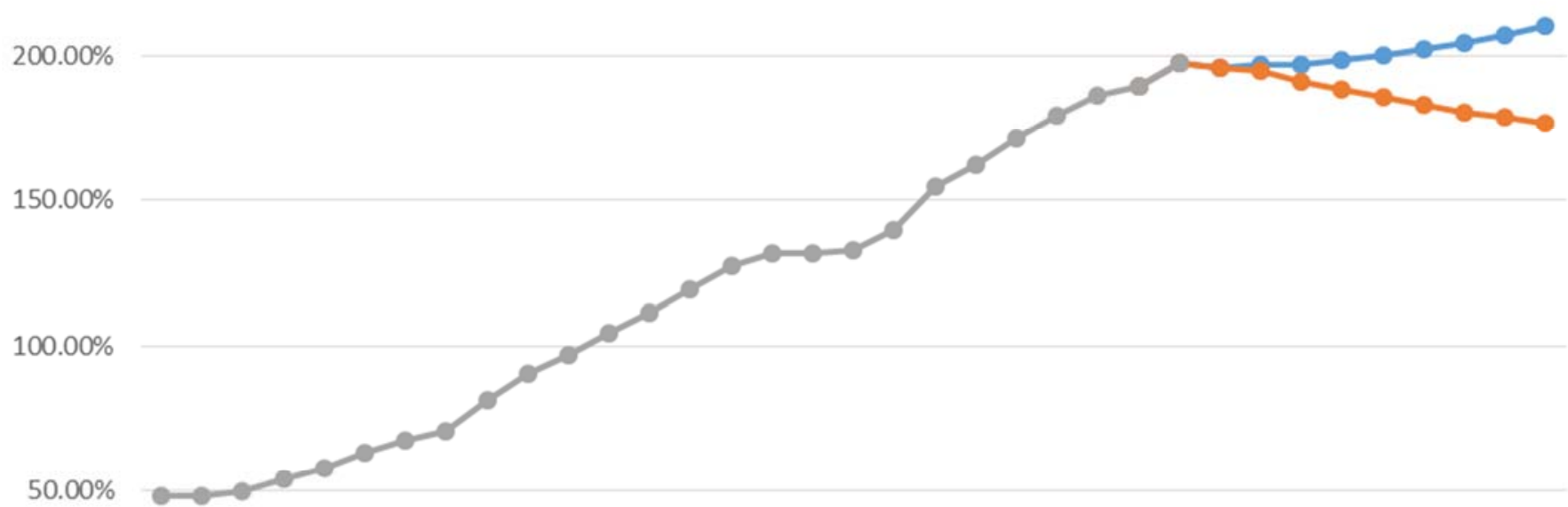

$0.00 \%$

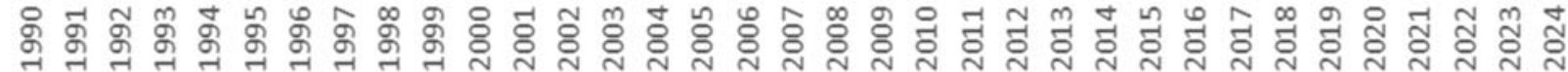

-Baseline case in EFPMLA of year 2016

- Recovery case in EFPMLA of year 2016

-Actual Value

Central and local governments debts are included. 
Figure 2-3: Economic Growth

\section{Growth Rate of Nominal GDP}

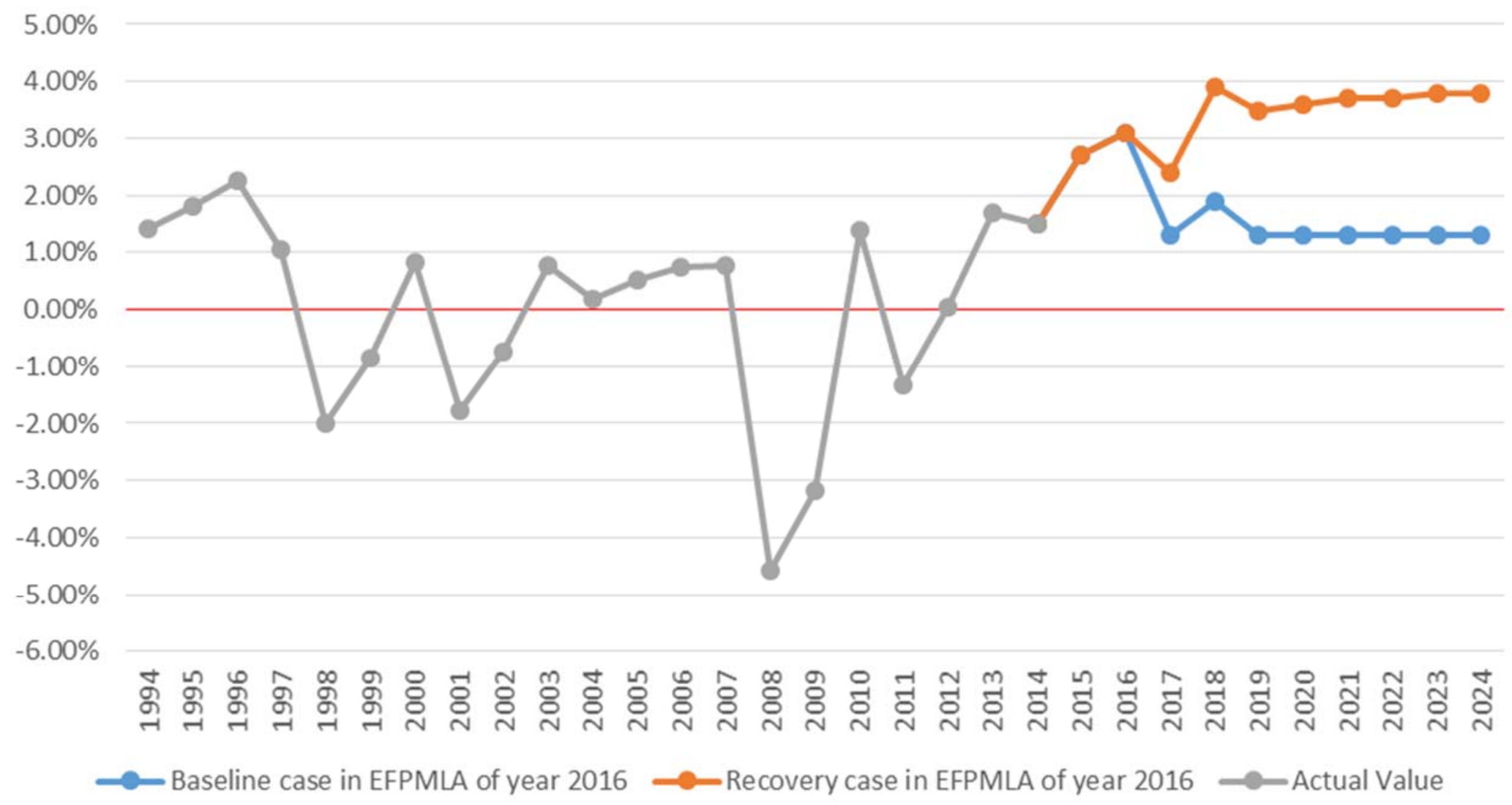


Figure 3-1: The GDP Ratio of the Expenditures of the Long-Term Care Insurance

\section{GDP RATIO OF THE FINANCIAL COST OF LONG- TERM CARE INSURANCE}

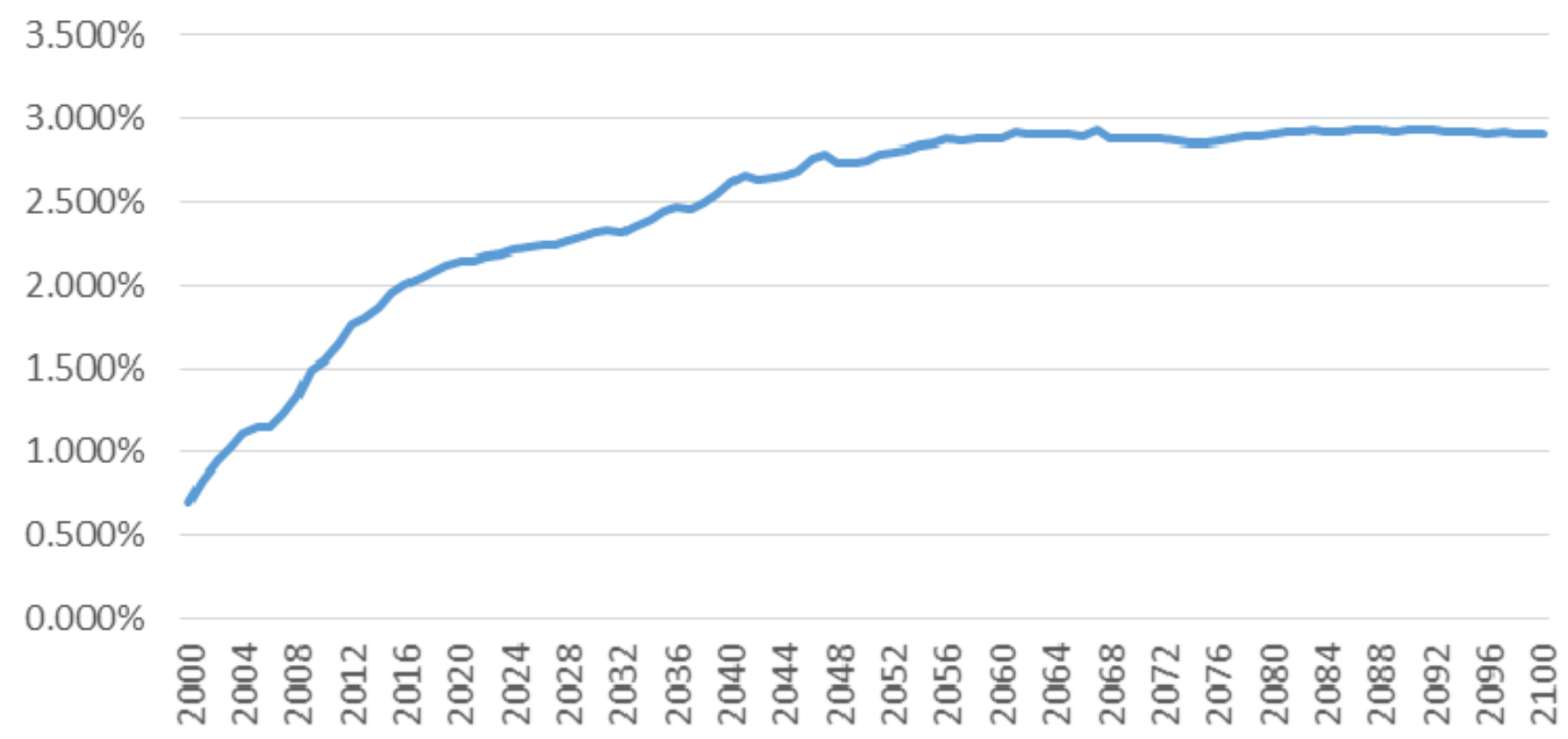

Until 2014, the actual data is used.

The amount of Co-payments paid by the insured is not included. 
Table 2: The Distribution of the Cost of the Long Term Care Insurance

\begin{tabular}{ccccc} 
& \multicolumn{2}{c}{ Contributins by } & & Tax \\
\cline { 2 - 3 } Year & 1st group & 2nd group & \\
$2000-2002$ & $17 \%$ & $33 \%$ & & $50 \%$ \\
$2003-2005$ & $18 \%$ & $32 \%$ & & $50 \%$ \\
$2006-2008$ & $19 \%$ & $31 \%$ & & $50 \%$ \\
$2009-2011$ & $20 \%$ & $30 \%$ & & $50 \%$ \\
$2012-2014$ & $21 \%$ & $29 \%$ & & $50 \%$ \\
$2015-2017$ & $22 \%$ & $28 \%$ & & $50 \%$ \\
$2018-2020$ & $23 \%$ & $27 \%$ & & $50 \%$ \\
$2021-2023$ & $23 \%$ & $27 \%$ & & $50 \%$ \\
$2024-2026$ & $24 \%$ & $26 \%$ & & $50 \%$ \\
$2027-2029$ & $24 \%$ & $26 \%$ & & $50 \%$ \\
$2030-2032$ & $24 \%$ & $26 \%$ & & $50 \%$ \\
$2033-2035$ & $25 \%$ & $25 \%$ & & $50 \%$ \\
$2036-2038$ & $26 \%$ & $24 \%$ & & $50 \%$ \\
$2039-2041$ & $27 \%$ & $23 \%$ & & $50 \%$ \\
$2042-2044$ & $27 \%$ & $23 \%$ & & $50 \%$ \\
$2045-2047$ & $28 \%$ & $22 \%$ & & $50 \%$ \\
$2048-2050$ & $28 \%$ & $22 \%$ & & $50 \%$ \\
$2051-2053$ & $28 \%$ & $22 \%$ & & $50 \%$ \\
$2054-2056$ & $28 \%$ & $22 \%$ & & $50 \%$ \\
$2057-2059$ & $28 \%$ & $22 \%$ & & $50 \%$ \\
$2060-2062$ & $28 \%$ & $22 \%$ & $50 \%$ \\
$2063-2065$ & $29 \%$ & $21 \%$ & & $50 \%$ \\
$2066-2068$ & $29 \%$ & $21 \%$ & & $50 \%$ \\
$2069-2071$ & $29 \%$ & $21 \%$ & & $50 \%$
\end{tabular}

$1^{\text {st }}$ Group: Age 65 and Over

$2^{\text {nd }}$ Group: Age $40-64$ 
Figure 3-2: The Government Expenditures

\section{GDP Ratio of Government Expenditures}

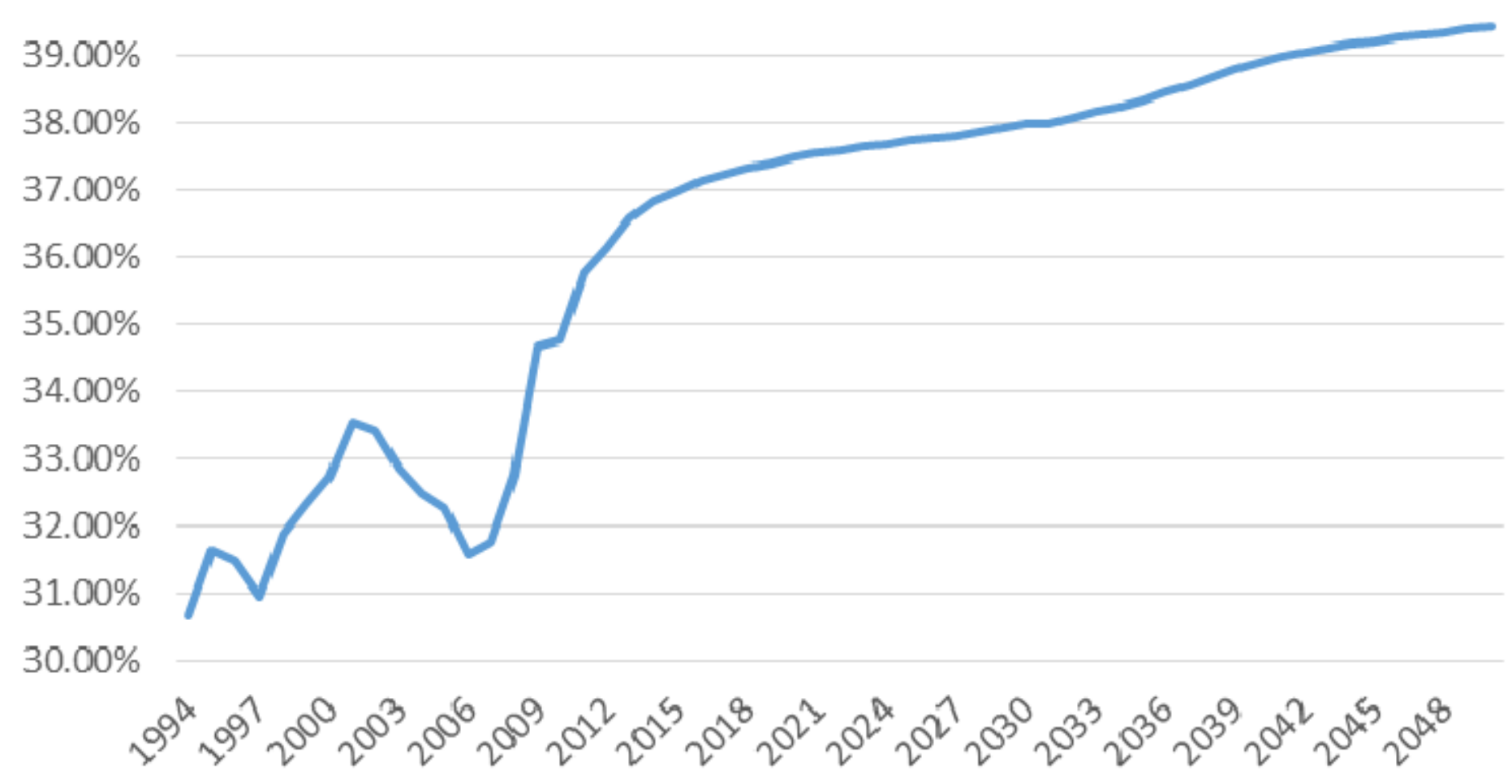


Figure 3-3: Future Deficits Ratio to GDP

The Future Scenario of Outstanding Government Debts

$250.00 \%$

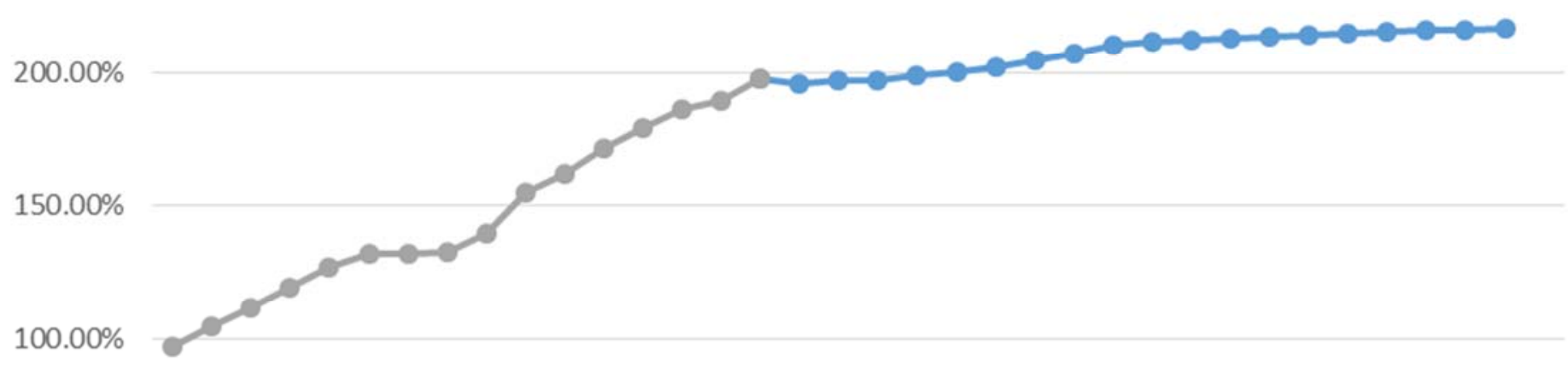

$50.00 \%$

$0.00 \%$

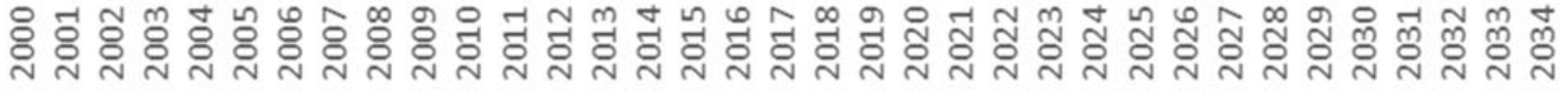

$\longrightarrow$ Baseline case in EFPMLA of year $2016 \longrightarrow$ Actual Value 
Figure 3-4: Public Pension Fund

\section{GDP Ratio of Public Pension Fund}

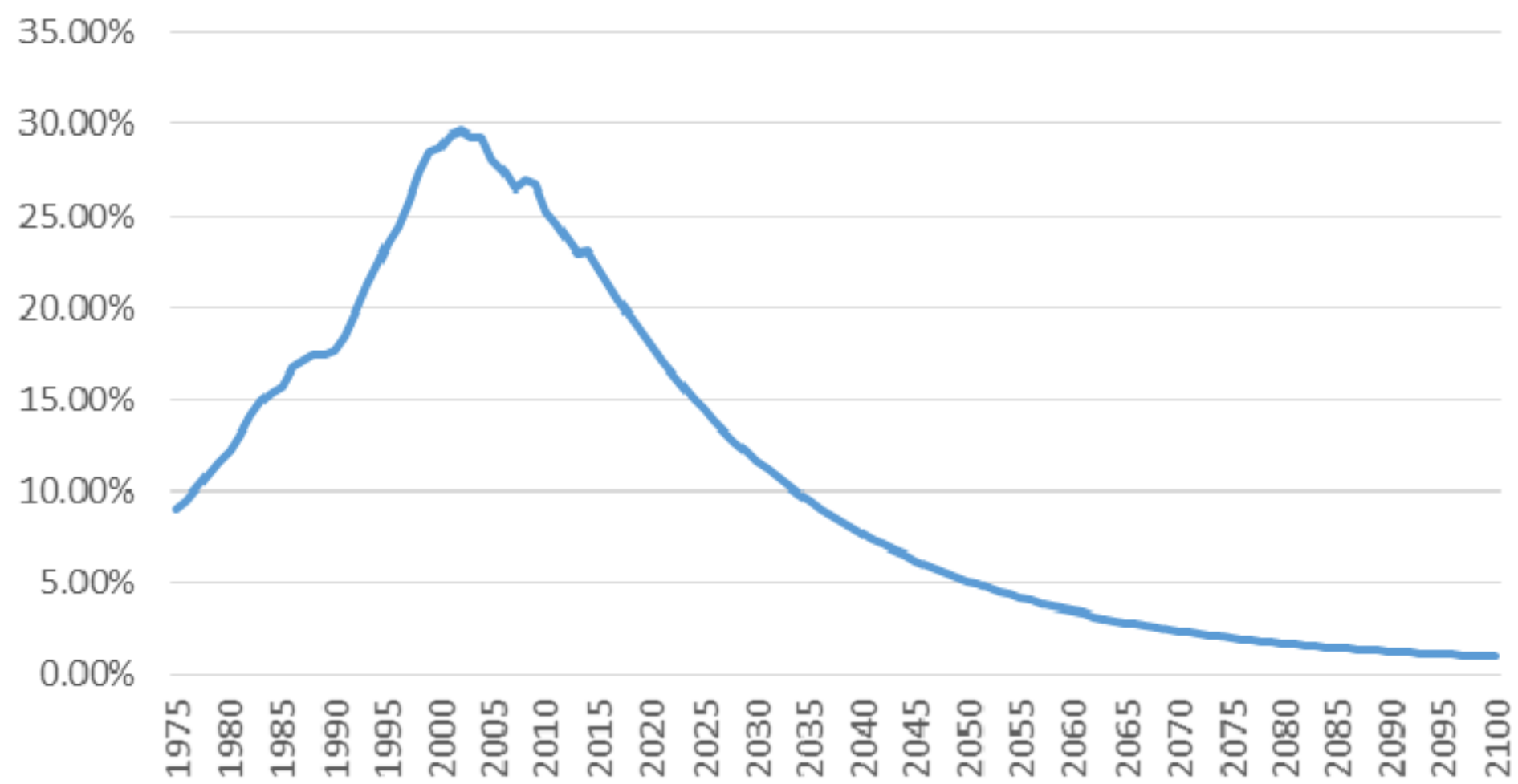


Table 3: The Values in Year 2012

\begin{tabular}{lrr}
\hline \hline \multicolumn{1}{c}{ Variables } & Actual & Model \\
GDP ratio of outstanding government bonds & $179.11 \%$ & $179.11 \%$ \\
GDP ratio of public pension fund & $23.79 \%$ & $23.79 \%$ \\
GDP ratio of government expenditures & $36.14 \%$ & $36.14 \%$ \\
GDP ratio of childcare benefits & $0.49 \%$ & $0.49 \%$ \\
GDP ratio of long-term care insurance expenditures & $1.758 \%$ & $1.758 \%$ \\
Primary balance & $-5.50 \%$ & $-5.00 \%$ \\
GDP growth rate (real) & $0.9 \%$ & $1.1 \%$ \\
National burden ratio & $40.6 \%$ & $40.61 \%$ \\
Fixed average amount of monthly contributions by the first group (age 65 and over) in the LTIC & 4972 yen & 5191 yen \\
Contribution rate for the second group (age 40 - 64) in the LTIC $*$ & $1.55 \%$ & $1.88 \%$ \\
Contribution rate in the public pension ** & $16.766 \%$ & $15.366 \%$ \\
Contribution rate in the public pension in year 2017*** & $18.3 \%$ & $18.29 \%$ \\
Wage income tax rate in year 2018** & $33.24 \%$ & $33.78 \%$ \\
& & \\
\hline
\end{tabular}

Sources: Ministry of Finance, Cabinet Office, and Ministry of Internal Affairs and Communications

*) The actual value is the contribution rate of the general insured in Kyokai Kempo

$* *)$ Both contribution rates are of the Kousei-Nenkin. The contribution rate is endogenously calculated until year 2017.

$* * * *)$ The wage income tax rate is endogenously calculated until year 2018 
Figure 4-1: Model Prediction for the Primary Balance

The GDP Ratio of Primary Balance

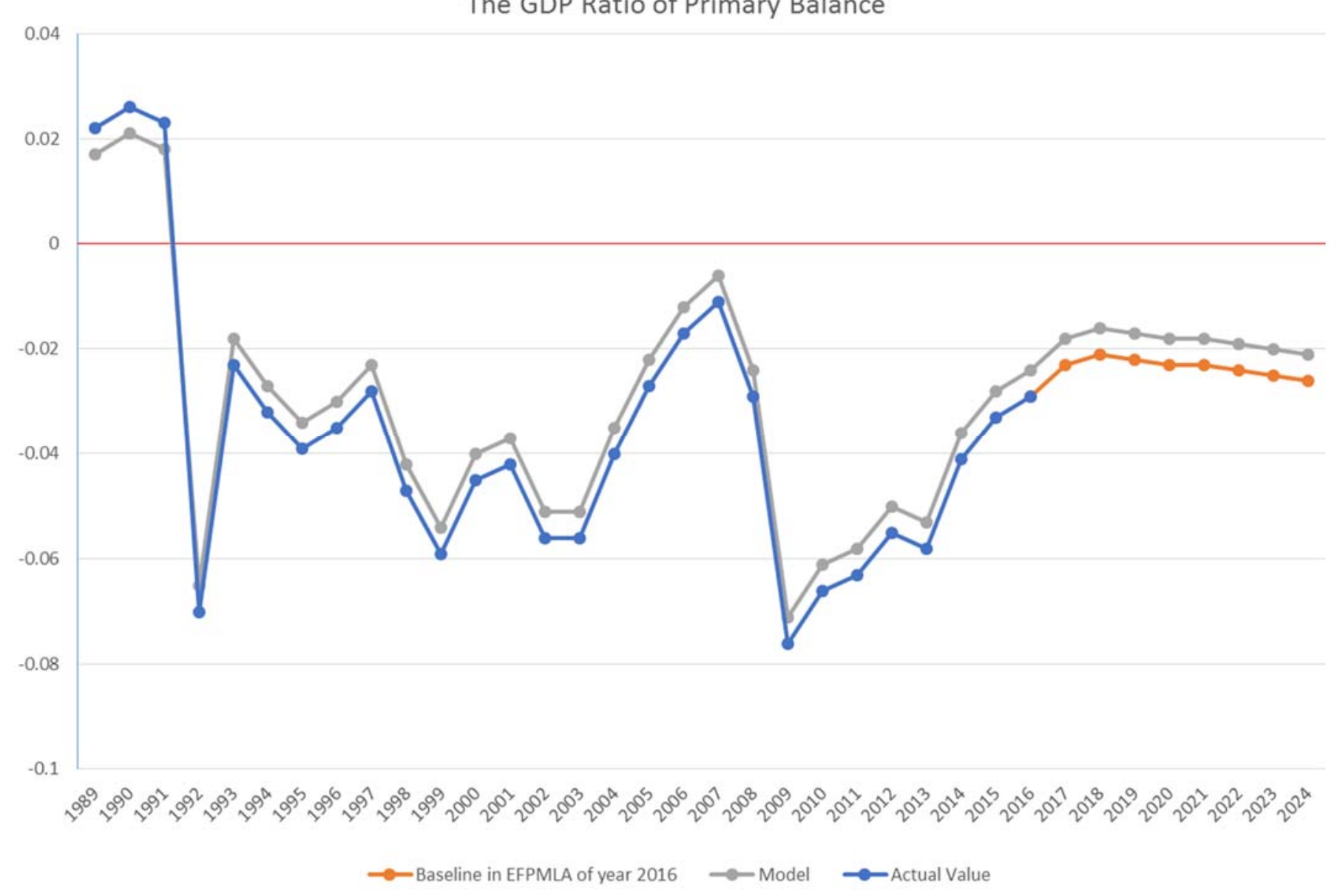

56 
Figure 4-2: Model Prediction for GDP Growth Rate

Growth Rate of Real GDP

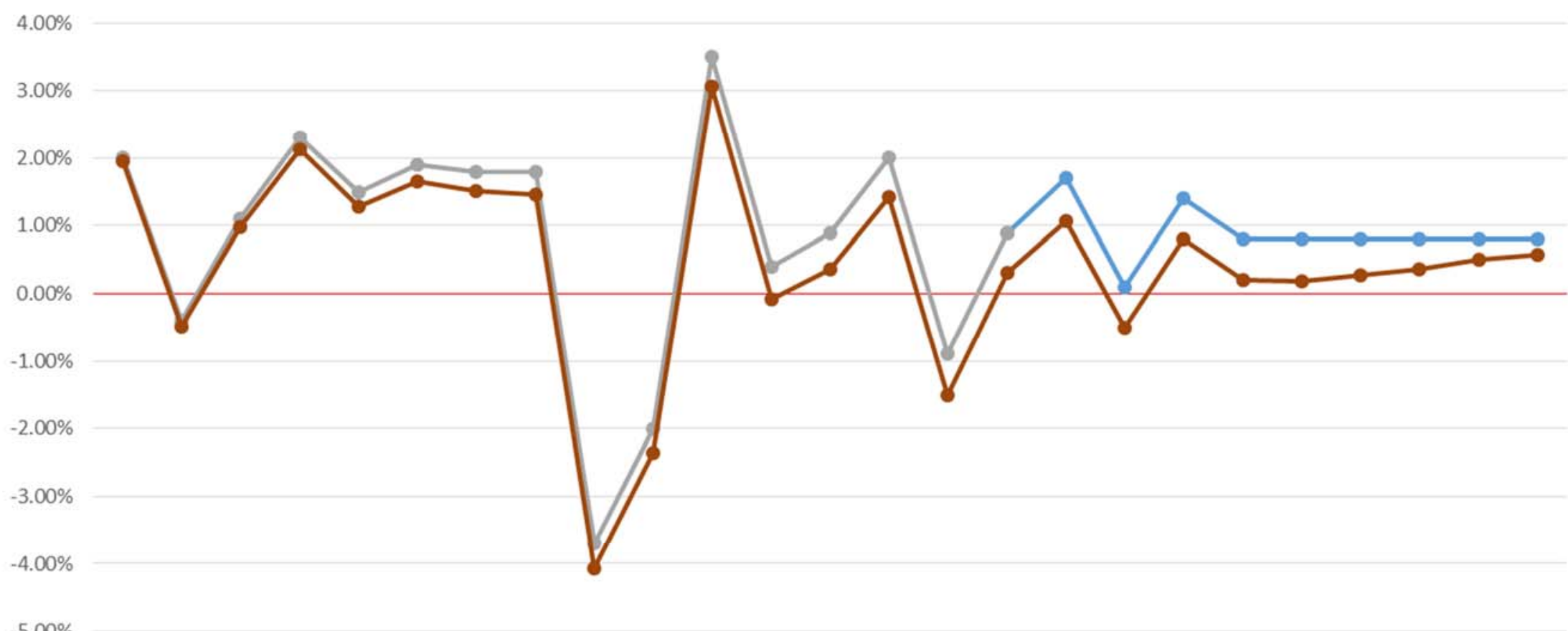

2000200120022003200420052006200720082009201020112012201320142015201620172018201920202021202220232024

—Baseline in EFPMLA of year 2016

$\longrightarrow$ Actual Value $\longrightarrow$ Model 
Figure 4-3: Parameter Value of Technological Progress $(\Omega)$

Technological Progress

(The Value of $\Omega$ )

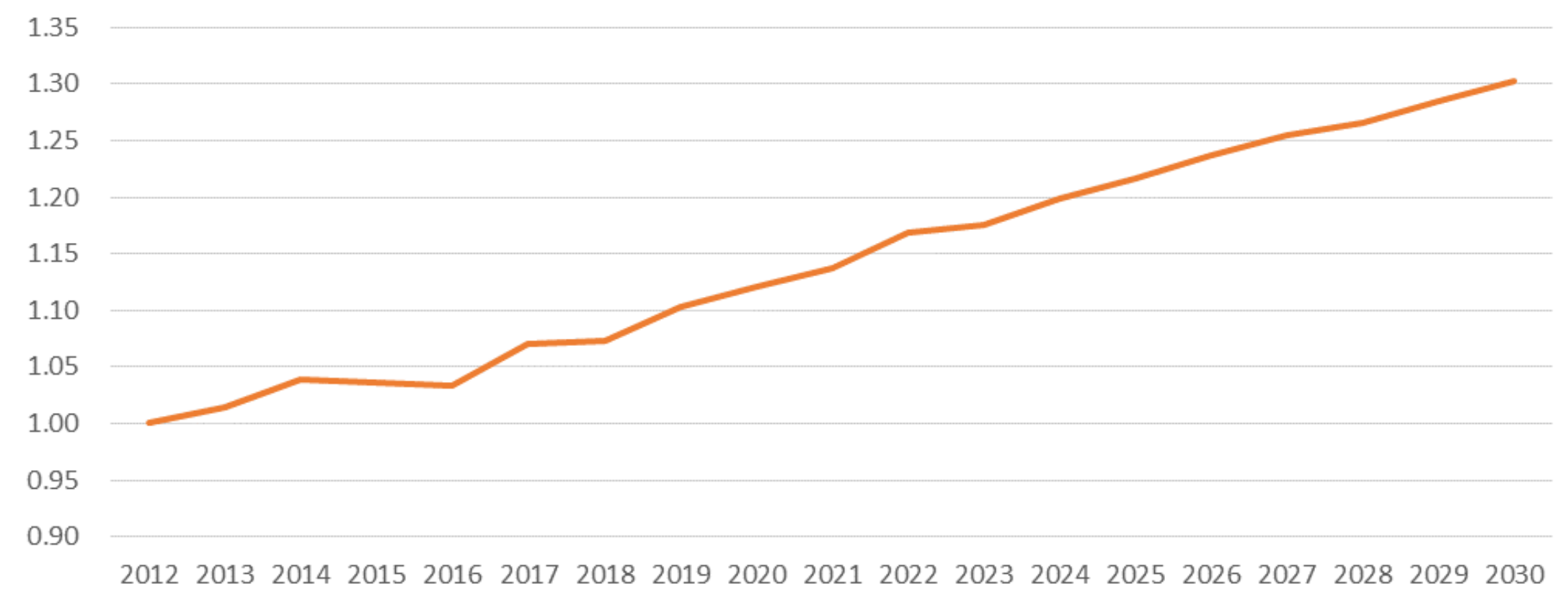


Table 4: The Impact of Population Aging on the LTCI in the benchmark

\begin{tabular}{|c|c|c|}
\hline & $\begin{array}{l}\text { The Fixed Amount of Monthly Contributions } \\
\text { of the First Group * (age } 65 \text { and over) (Unit: yen) }\end{array}$ & Contribution Rate for the Second Group (age 40 - 64) \\
\hline 2017 & 5,514 & $2.07 \%$ \\
\hline 2018 & 5,620 & $2.14 \%$ \\
\hline 2019 & 5,739 & $2.23 \%$ \\
\hline 2020 & 5,846 & $2.29 \%$ \\
\hline 2021 & 5,954 & $2.37 \%$ \\
\hline 2022 & 6,030 & $2.43 \%$ \\
\hline 2023 & 6,201 & $2.55 \%$ \\
\hline 2024 & 6,349 & $2.65 \%$ \\
\hline 2025 & 6,496 & $2.76 \%$ \\
\hline 2026 & 6,627 & $2.86 \%$ \\
\hline 2027 & 6,754 & $2.96 \%$ \\
\hline 2028 & 6,878 & $3.06 \%$ \\
\hline 2029 & 7,030 & $3.18 \%$ \\
\hline 2030 & 7,180 & $3.30 \%$ \\
\hline 2031 & 7,292 & $3.42 \%$ \\
\hline 2032 & 7,420 & $3.50 \%$ \\
\hline 2033 & 7,522 & $3.59 \%$ \\
\hline 2034 & 7,649 & $3.68 \%$ \\
\hline 2035 & 7,739 & $3.86 \%$ \\
\hline 2036 & 7,907 & $3.98 \%$ \\
\hline 2037 & 7,859 & $4.03 \%$ \\
\hline 2038 & 7,903 & $4.06 \%$ \\
\hline 2039 & 7,938 & $4.07 \%$ \\
\hline 2040 & 8,075 & $4.17 \%$ \\
\hline 2041 & 8,153 & $4.34 \%$ \\
\hline 2042 & 8,171 & $4.34 \%$ \\
\hline 2043 & 8,168 & $4.33 \%$ \\
\hline 2044 & 8,164 & $4.31 \%$ \\
\hline 2045 & 8,181 & $4.31 \%$ \\
\hline 2046 & 8,300 & $4.41 \%$ \\
\hline 2047 & 8,388 & $4.58 \%$ \\
\hline 2048 & 8,417 & $4.59 \%$ \\
\hline 2049 & 8,425 & $4.58 \%$ \\
\hline 2050 & 8,419 & $4.56 \%$ \\
\hline 2051 & 8,473 & $4.61 \%$ \\
\hline 2052 & 8,547 & $4.66 \%$ \\
\hline 2053 & 8,631 & $4.72 \%$ \\
\hline 2054 & 8,652 & $4.86 \%$ \\
\hline 2055 & 8,772 & $4.96 \%$ \\
\hline 2056 & 8,964 & $5.12 \%$ \\
\hline 2057 & 9,097 & $5.24 \%$ \\
\hline 2058 & 9,180 & $5.43 \%$ \\
\hline 2059 & 9,328 & $5.57 \%$ \\
\hline 2060 & 9,457 & $5.68 \%$ \\
\hline
\end{tabular}

*) The fixed monthly amount of contributions of the first group is the average amount of Kyokai Kempo.. The contribution rate for the second group is the rate in Kyokai Kempo. 
Table 5-1: The Impact of Policy 1 (Higher Co-payments)

\begin{tabular}{|c|c|c|c|c|c|c|}
\hline & \multicolumn{3}{|c|}{ Co-Payment Rate } & \multicolumn{3}{|c|}{ Co-Payment Rate } \\
\hline & $\begin{array}{c}10 \% \\
\text { (Benchmark) }\end{array}$ & $20 \%$ & $30 \%$ & $\begin{array}{c}10 \% \\
\text { (Benchmark) }\end{array}$ & $20 \%$ & $30 \%$ \\
\hline & \multicolumn{3}{|c|}{$\begin{array}{l}\text { The Fixed Amount of Monthly Contributions of } \\
\text { the First Group (age } 65 \text { and over) (Unit: yen) }\end{array}$} & \multicolumn{3}{|c|}{ Contribution Rate for the Second Group (age 40 - 64) } \\
\hline Year & & & & & & \\
\hline 2017 & 5,514 & 5,384 & 5,256 & $2.07 \%$ & $1.99 \%$ & $1.90 \%$ \\
\hline 2018 & 5,620 & 5,491 & 5,361 & $2.14 \%$ & $2.06 \%$ & $1.97 \%$ \\
\hline 2019 & 5,739 & 5,610 & 5,480 & $2.23 \%$ & $2.14 \%$ & $2.05 \%$ \\
\hline 2020 & 5,846 & 5,733 & 5,601 & $2.29 \%$ & $2.22 \%$ & $2.14 \%$ \\
\hline 2021 & 5,954 & 5,833 & 5,700 & $2.37 \%$ & $2.29 \%$ & $2.20 \%$ \\
\hline 2022 & 6,030 & 5,883 & 5,770 & $2.43 \%$ & $2.33 \%$ & $2.26 \%$ \\
\hline 2023 & 6,201 & 6,047 & 5,922 & $2.55 \%$ & $2.44 \%$ & $2.36 \%$ \\
\hline 2024 & 6,349 & 6,188 & 6,055 & $2.65 \%$ & $2.54 \%$ & $2.45 \%$ \\
\hline 2025 & 6,496 & 6,327 & 6,186 & $2.76 \%$ & $2.65 \%$ & $2.55 \%$ \\
\hline 2026 & 6,627 & 6,451 & 6,297 & $2.86 \%$ & $2.74 \%$ & $2.64 \%$ \\
\hline 2027 & 6,754 & 6,568 & 6,402 & $2.96 \%$ & $2.84 \%$ & $2.71 \%$ \\
\hline 2028 & 6,878 & 6,686 & 6,482 & $3.06 \%$ & $2.93 \%$ & $2.77 \%$ \\
\hline 2029 & 7,030 & 6,832 & 6,616 & $3.18 \%$ & $3.04 \%$ & $2.87 \%$ \\
\hline 2030 & 7,180 & 6,973 & 6,753 & $3.30 \%$ & $3.15 \%$ & $2.97 \%$ \\
\hline 2031 & 7,292 & 7,080 & 6,853 & $3.42 \%$ & $3.27 \%$ & $3.08 \%$ \\
\hline 2032 & 7,420 & 7,193 & 6,961 & $3.50 \%$ & $3.33 \%$ & $3.14 \%$ \\
\hline 2033 & 7,522 & 7,296 & 7,057 & $3.59 \%$ & $3.42 \%$ & $3.21 \%$ \\
\hline 2034 & 7,649 & 7,415 & 7,171 & $3.68 \%$ & $3.50 \%$ & $3.29 \%$ \\
\hline 2035 & 7,739 & 7,496 & 7,242 & $3.86 \%$ & $3.67 \%$ & $3.45 \%$ \\
\hline 2036 & 7,907 & 7,655 & 7,392 & $3.98 \%$ & $3.78 \%$ & $3.55 \%$ \\
\hline 2037 & 7,859 & 7,604 & 7,413 & $4.03 \%$ & $3.83 \%$ & $3.56 \%$ \\
\hline 2038 & 7,903 & 7,642 & 7,374 & $4.06 \%$ & $3.85 \%$ & $3.61 \%$ \\
\hline 2039 & 7,938 & 7,677 & 7,406 & $4.07 \%$ & $3.86 \%$ & $3.62 \%$ \\
\hline 2040 & 8,075 & 7,806 & 7,529 & $4.17 \%$ & $3.95 \%$ & $3.70 \%$ \\
\hline 2041 & 8,153 & 7,877 & 7,590 & $4.34 \%$ & $4.11 \%$ & $3.85 \%$ \\
\hline 2042 & 8,171 & 7,893 & 7,608 & $4.34 \%$ & $4.12 \%$ & $3.85 \%$ \\
\hline 2043 & 8,168 & 7,888 & 7,603 & $4.33 \%$ & $4.10 \%$ & $3.83 \%$ \\
\hline 2044 & 8,164 & 7,885 & 7,594 & $4.31 \%$ & $4.08 \%$ & $3.82 \%$ \\
\hline 2045 & 8,181 & 7,901 & 7,611 & $4.31 \%$ & $4.08 \%$ & $3.81 \%$ \\
\hline 2046 & 8,300 & 8,013 & 7,722 & $4.41 \%$ & $4.17 \%$ & $3.89 \%$ \\
\hline 2047 & 8,388 & 8,096 & 7,874 & $4.58 \%$ & $4.33 \%$ & $4.00 \%$ \\
\hline 2048 & 8,417 & 8,123 & 7,822 & $4.59 \%$ & $4.34 \%$ & $4.05 \%$ \\
\hline 2049 & 8,425 & 8,130 & 7,831 & $4.58 \%$ & $4.33 \%$ & $4.04 \%$ \\
\hline 2050 & 8,419 & 8,119 & 7,821 & $4.56 \%$ & $4.31 \%$ & $4.02 \%$ \\
\hline 2051 & 8,473 & 8,174 & 7,873 & $4.61 \%$ & $4.35 \%$ & $4.05 \%$ \\
\hline 2052 & 8,547 & 8,245 & 7,942 & $4.66 \%$ & $4.40 \%$ & $4.10 \%$ \\
\hline 2053 & 8,631 & 8,328 & 8,020 & $4.72 \%$ & $4.46 \%$ & $4.15 \%$ \\
\hline 2054 & 8,652 & 8,424 & 8,114 & $4.86 \%$ & $4.54 \%$ & $4.23 \%$ \\
\hline 2055 & 8,772 & 8,459 & 8,220 & $4.96 \%$ & $4.68 \%$ & $4.32 \%$ \\
\hline 2056 & 8,964 & 8,645 & 8,316 & $5.12 \%$ & $4.84 \%$ & $4.52 \%$ \\
\hline 2057 & 9,097 & 8,773 & 8,439 & $5.24 \%$ & $4.95 \%$ & $4.62 \%$ \\
\hline 2058 & 9,180 & 8,929 & 8,588 & $5.43 \%$ & $5.09 \%$ & $4.75 \%$ \\
\hline 2059 & 9,328 & 9,073 & 8,730 & $5.57 \%$ & $5.21 \%$ & $4.87 \%$ \\
\hline 2060 & 9,457 & 9,116 & 8,851 & $5.68 \%$ & $5.37 \%$ & $4.97 \%$ \\
\hline
\end{tabular}


Table 5-2: The Impact of Policy 1 (Percentage changes from the benchmark)

\begin{tabular}{|c|c|c|c|c|}
\hline & \multicolumn{2}{|c|}{ Co-Payment Rate } & \multicolumn{2}{|c|}{ Co-Payment Rate } \\
\hline & $20 \%$ & $30 \%$ & $20 \%$ & $30 \%$ \\
\hline & $\begin{array}{l}\text { The Fixed Amou } \\
\text { the First Grou }\end{array}$ & $\begin{array}{l}\text { Contributions of } \\
\text { er) (Unit: yen) }\end{array}$ & Contribution $\mathrm{Ra}$ & Group (age 40 - \\
\hline \multicolumn{5}{|l|}{ Year } \\
\hline 2017 & $-2.37 \%$ & $-4.69 \%$ & $-4.00 \%$ & $-8.23 \%$ \\
\hline 2018 & $-2.30 \%$ & $-4.61 \%$ & $-3.81 \%$ & $-8.04 \%$ \\
\hline 2019 & $-2.25 \%$ & $-4.52 \%$ & $-3.99 \%$ & $-7.95 \%$ \\
\hline 2020 & $-1.94 \%$ & $-4.18 \%$ & $-3.00 \%$ & $-6.71 \%$ \\
\hline 2021 & $-2.04 \%$ & $-4.27 \%$ & $-3.25 \%$ & $-6.99 \%$ \\
\hline 2022 & $-2.43 \%$ & $-4.31 \%$ & $-3.95 \%$ & $-7.10 \%$ \\
\hline 2023 & $-2.48 \%$ & $-4.49 \%$ & $-4.14 \%$ & $-7.32 \%$ \\
\hline 2024 & $-2.54 \%$ & $-4.64 \%$ & $-4.07 \%$ & $-7.38 \%$ \\
\hline 2025 & $-2.60 \%$ & $-4.78 \%$ & $-4.07 \%$ & $-7.68 \%$ \\
\hline 2026 & $-2.65 \%$ & $-4.98 \%$ & $-4.11 \%$ & $-7.85 \%$ \\
\hline 2027 & $-2.75 \%$ & $-5.20 \%$ & $-4.19 \%$ & $-8.37 \%$ \\
\hline 2028 & $-2.79 \%$ & $-5.76 \%$ & $-4.37 \%$ & $-9.56 \%$ \\
\hline 2029 & $-2.82 \%$ & $-5.90 \%$ & $-4.45 \%$ & $-9.65 \%$ \\
\hline 2030 & $-2.88 \%$ & $-5.95 \%$ & $-4.65 \%$ & $-9.98 \%$ \\
\hline 2031 & $-2.91 \%$ & $-6.03 \%$ & $-4.51 \%$ & $-9.98 \%$ \\
\hline 2032 & $-3.05 \%$ & $-6.19 \%$ & $-4.73 \%$ & $-10.23 \%$ \\
\hline 2033 & $-3.01 \%$ & $-6.18 \%$ & $-4.85 \%$ & $-10.45 \%$ \\
\hline 2034 & $-3.05 \%$ & $-6.25 \%$ & $-4.81 \%$ & $-10.50 \%$ \\
\hline 2035 & $-3.14 \%$ & $-6.43 \%$ & $-4.94 \%$ & $-10.62 \%$ \\
\hline 2036 & $-3.19 \%$ & $-6.51 \%$ & $-4.97 \%$ & $-10.73 \%$ \\
\hline 2037 & $-3.24 \%$ & $-5.67 \%$ & $-4.89 \%$ & $-11.74 \%$ \\
\hline 2038 & $-3.31 \%$ & $-6.70 \%$ & $-5.18 \%$ & $-11.06 \%$ \\
\hline 2039 & $-3.29 \%$ & $-6.70 \%$ & $-5.14 \%$ & $-11.12 \%$ \\
\hline 2040 & $-3.33 \%$ & $-6.76 \%$ & $-5.25 \%$ & $-11.29 \%$ \\
\hline 2041 & $-3.39 \%$ & $-6.91 \%$ & $-5.23 \%$ & $-11.30 \%$ \\
\hline 2042 & $-3.40 \%$ & $-6.89 \%$ & $-5.16 \%$ & $-11.25 \%$ \\
\hline 2043 & $-3.43 \%$ & $-6.92 \%$ & $-5.38 \%$ & $-11.53 \%$ \\
\hline 2044 & $-3.42 \%$ & $-6.99 \%$ & $-5.28 \%$ & $-11.48 \%$ \\
\hline 2045 & $-3.42 \%$ & $-6.97 \%$ & $-5.33 \%$ & $-11.52 \%$ \\
\hline 2046 & $-3.46 \%$ & $-6.97 \%$ & $-5.53 \%$ & $-11.79 \%$ \\
\hline 2047 & $-3.48 \%$ & $-6.13 \%$ & $-5.39 \%$ & $-12.76 \%$ \\
\hline 2048 & $-3.49 \%$ & $-7.07 \%$ & $-5.49 \%$ & $-11.79 \%$ \\
\hline 2049 & $-3.50 \%$ & $-7.05 \%$ & $-5.52 \%$ & $-11.82 \%$ \\
\hline 2050 & $-3.56 \%$ & $-7.10 \%$ & $-5.42 \%$ & $-11.77 \%$ \\
\hline 2051 & $-3.53 \%$ & $-7.09 \%$ & $-5.65 \%$ & $-12.06 \%$ \\
\hline 2052 & $-3.53 \%$ & $-7.07 \%$ & $-5.64 \%$ & $-12.02 \%$ \\
\hline 2053 & $-3.51 \%$ & $-7.08 \%$ & $-5.53 \%$ & $-11.97 \%$ \\
\hline 2054 & $-2.64 \%$ & $-6.22 \%$ & $-6.67 \%$ & $-12.99 \%$ \\
\hline 2055 & $-3.56 \%$ & $-6.29 \%$ & $-5.55 \%$ & $-12.88 \%$ \\
\hline 2056 & $-3.56 \%$ & $-7.22 \%$ & $-5.39 \%$ & $-11.67 \%$ \\
\hline 2057 & $-3.56 \%$ & $-7.24 \%$ & $-5.50 \%$ & $-11.76 \%$ \\
\hline 2058 & $-2.74 \%$ & $-6.45 \%$ & $-6.30 \%$ & $-12.49 \%$ \\
\hline 2059 & $-2.74 \%$ & $-6.41 \%$ & $-6.38 \%$ & $-12.61 \%$ \\
\hline 2060 & $-3.61 \%$ & $-6.41 \%$ & $-5.38 \%$ & $-12.58 \%$ \\
\hline
\end{tabular}


Table 5-3: The Impact of Policy 2 (Earlier Contributing Age)

\begin{tabular}{|c|c|c|c|c|c|c|}
\hline & \multicolumn{3}{|c|}{ Starting Age of Contribution } & \multicolumn{3}{|c|}{ Co-Payment Rate } \\
\hline & $\begin{array}{c}\text { Age } 40 \\
\text { (Benchmark) }\end{array}$ & Age 35 & Age 30 & $\begin{array}{c}\text { Age } 40 \\
\text { (Benchmark) }\end{array}$ & Age 35 & Age 30 \\
\hline & \multicolumn{3}{|c|}{$\begin{array}{l}\text { The Fixed Amount of Monthly Contributions of the } \\
\text { First Group (age } 65 \text { and over) (Unit: yen) }\end{array}$} & \multicolumn{3}{|c|}{ Contribution Rate for the Second Group (age 40 - 64) } \\
\hline Year & & & & & & \\
\hline 2017 & 5,514 & 5,214 & 4,997 & $2.07 \%$ & $1.87 \%$ & $1.74 \%$ \\
\hline 2018 & 5,620 & 5,319 & 5,100 & $2.14 \%$ & $1.94 \%$ & $1.81 \%$ \\
\hline 2019 & 5,739 & 5,435 & 5,215 & $2.23 \%$ & $2.02 \%$ & $1.89 \%$ \\
\hline 2020 & 5,846 & 5,538 & 5,319 & $2.29 \%$ & $2.09 \%$ & $1.95 \%$ \\
\hline 2021 & 5,954 & 5,644 & 5,421 & $2.37 \%$ & $2.16 \%$ & $2.02 \%$ \\
\hline 2022 & 6,030 & 5,722 & 5,499 & $2.43 \%$ & $2.22 \%$ & $2.08 \%$ \\
\hline 2023 & 6,201 & 5,887 & 5,653 & $2.55 \%$ & $2.32 \%$ & $2.18 \%$ \\
\hline 2024 & 6,349 & 6,029 & 5,789 & $2.65 \%$ & $2.42 \%$ & $2.27 \%$ \\
\hline 2025 & 6,496 & 6,173 & 5,924 & $2.76 \%$ & $2.53 \%$ & $2.37 \%$ \\
\hline 2026 & 6,627 & 6,302 & 6,040 & $2.86 \%$ & $2.62 \%$ & $2.46 \%$ \\
\hline 2027 & 6,754 & 6,427 & 6,156 & $2.96 \%$ & $2.72 \%$ & $2.54 \%$ \\
\hline 2028 & 6,878 & 6,544 & 6,262 & $3.06 \%$ & $2.81 \%$ & $2.62 \%$ \\
\hline 2029 & 7,030 & 6,687 & 6,395 & $3.18 \%$ & $2.91 \%$ & $2.72 \%$ \\
\hline 2030 & 7,180 & 6,824 & 6,524 & $3.30 \%$ & $3.01 \%$ & $2.81 \%$ \\
\hline 2031 & 7,292 & 6,926 & 6,619 & $3.42 \%$ & $3.12 \%$ & $2.91 \%$ \\
\hline 2032 & 7,420 & 7,038 & 6,725 & $3.50 \%$ & $3.18 \%$ & $2.97 \%$ \\
\hline 2033 & 7,522 & 7,130 & 6,815 & $3.59 \%$ & $3.26 \%$ & $3.04 \%$ \\
\hline 2034 & 7,649 & 7,246 & 6,927 & $3.68 \%$ & $3.34 \%$ & $3.12 \%$ \\
\hline 2035 & 7,739 & 7,407 & 7,084 & $3.86 \%$ & $3.46 \%$ & $3.23 \%$ \\
\hline 2036 & 7,907 & 7,562 & 7,233 & $3.98 \%$ & $3.56 \%$ & $3.33 \%$ \\
\hline 2037 & 7,859 & 7,512 & 7,267 & $4.03 \%$ & $3.61 \%$ & $3.34 \%$ \\
\hline 2038 & 7,903 & 7,558 & 7,318 & $4.06 \%$ & $3.64 \%$ & $3.36 \%$ \\
\hline 2039 & 7,938 & 7,596 & 7,269 & $4.07 \%$ & $3.65 \%$ & $3.42 \%$ \\
\hline 2040 & 8,075 & 7,651 & 7,396 & $4.17 \%$ & $3.79 \%$ & $3.50 \%$ \\
\hline 2041 & 8,153 & 7,808 & 7,546 & $4.34 \%$ & $3.90 \%$ & $3.61 \%$ \\
\hline 2042 & 8,171 & 7,825 & 7,488 & $4.34 \%$ & $3.91 \%$ & $3.66 \%$ \\
\hline 2043 & 8,168 & 7,824 & 7,483 & $4.33 \%$ & $3.90 \%$ & $3.65 \%$ \\
\hline 2044 & 8,164 & 7,821 & 7,484 & $4.31 \%$ & $3.88 \%$ & $3.64 \%$ \\
\hline 2045 & 8,181 & 7,836 & 7,504 & $4.31 \%$ & $3.88 \%$ & $3.64 \%$ \\
\hline 2046 & 8,300 & 7,870 & 7,613 & $4.41 \%$ & $4.01 \%$ & $3.72 \%$ \\
\hline 2047 & 8,388 & 8,022 & 7,762 & $4.58 \%$ & $4.12 \%$ & $3.83 \%$ \\
\hline 2048 & 8,417 & 8,053 & 7,709 & $4.59 \%$ & $4.13 \%$ & $3.88 \%$ \\
\hline 2049 & 8,425 & 8,065 & 7,722 & $4.58 \%$ & $4.13 \%$ & $3.88 \%$ \\
\hline 2050 & 8,419 & 8,066 & 7,723 & $4.56 \%$ & $4.12 \%$ & $3.87 \%$ \\
\hline 2051 & 8,473 & 8,122 & 7,782 & $4.61 \%$ & $4.16 \%$ & $3.91 \%$ \\
\hline 2052 & 8,547 & 8,108 & 7,858 & $4.66 \%$ & $4.25 \%$ & $3.96 \%$ \\
\hline 2053 & 8,631 & 8,189 & 7,941 & $4.72 \%$ & $4.31 \%$ & $4.02 \%$ \\
\hline 2054 & 8,652 & 8,283 & 8,030 & $4.86 \%$ & $4.39 \%$ & $4.09 \%$ \\
\hline 2055 & 8,772 & 8,397 & 8,054 & $4.96 \%$ & $4.48 \%$ & $4.22 \%$ \\
\hline 2056 & 8,964 & 8,586 & 8,234 & $5.12 \%$ & $4.63 \%$ & $4.37 \%$ \\
\hline 2057 & 9,097 & 8,633 & 8,360 & $5.24 \%$ & $4.79 \%$ & $4.47 \%$ \\
\hline 2058 & 9,180 & 8,792 & 8,509 & $5.43 \%$ & $4.93 \%$ & $4.59 \%$ \\
\hline 2059 & 9,328 & 8,940 & 8,563 & $5.57 \%$ & $5.05 \%$ & $4.75 \%$ \\
\hline 2060 & 9,457 & 9,065 & 8,674 & $5.68 \%$ & $5.15 \%$ & $4.85 \%$ \\
\hline
\end{tabular}




\section{Table 5-4: The Impact of Policy 2 (Percentage changes from the benchmark)}

\begin{tabular}{|c|c|c|c|c|}
\hline & \multicolumn{2}{|c|}{ Starting Age of Contribution } & \multicolumn{2}{|c|}{ Starting Age of Contribution } \\
\hline & Age 35 & Age 30 & Age 35 & Age 30 \\
\hline & $\begin{array}{l}\text { The Fixed Amou } \\
\text { the First Group }\end{array}$ & $\begin{array}{l}\text { ontributions of } \\
\text { er) (Unit: yen) }\end{array}$ & Contribution Rate & oup (age $40-64$ ) \\
\hline \multicolumn{5}{|l|}{ Year } \\
\hline 2017 & $-5.44 \%$ & $-9.37 \%$ & $-9.47 \%$ & $-15.74 \%$ \\
\hline 2018 & $-5.36 \%$ & $-9.25 \%$ & $-9.36 \%$ & $-15.47 \%$ \\
\hline 2019 & $-5.29 \%$ & $-9.13 \%$ & $-9.40 \%$ & $-15.36 \%$ \\
\hline 2020 & $-5.26 \%$ & $-9.02 \%$ & $-8.90 \%$ & $-14.81 \%$ \\
\hline 2021 & $-5.20 \%$ & $-8.95 \%$ & $-8.95 \%$ & $-14.69 \%$ \\
\hline 2022 & $-5.11 \%$ & $-8.81 \%$ & $-8.84 \%$ & $-14.51 \%$ \\
\hline 2023 & $-5.06 \%$ & $-8.83 \%$ & $-8.89 \%$ & $-14.44 \%$ \\
\hline 2024 & $-5.04 \%$ & $-8.82 \%$ & $-8.58 \%$ & $-14.20 \%$ \\
\hline 2025 & $-4.97 \%$ & $-8.81 \%$ & $-8.40 \%$ & $-14.20 \%$ \\
\hline 2026 & $-4.91 \%$ & $-8.86 \%$ & $-8.28 \%$ & $-14.13 \%$ \\
\hline 2027 & $-4.84 \%$ & $-8.86 \%$ & $-8.25 \%$ & $-14.19 \%$ \\
\hline 2028 & $-4.86 \%$ & $-8.96 \%$ & $-8.29 \%$ & $-14.34 \%$ \\
\hline 2029 & $-4.88 \%$ & $-9.03 \%$ & $-8.40 \%$ & $-14.51 \%$ \\
\hline 2030 & $-4.96 \%$ & $-9.14 \%$ & $-8.66 \%$ & $-14.90 \%$ \\
\hline 2031 & $-5.02 \%$ & $-9.23 \%$ & $-8.67 \%$ & $-14.90 \%$ \\
\hline 2032 & $-5.15 \%$ & $-9.37 \%$ & $-9.02 \%$ & $-15.23 \%$ \\
\hline 2033 & $-5.21 \%$ & $-9.41 \%$ & $-9.20 \%$ & $-15.36 \%$ \\
\hline 2034 & $-5.27 \%$ & $-9.44 \%$ & $-9.19 \%$ & $-15.30 \%$ \\
\hline 2035 & $-4.29 \%$ & $-8.47 \%$ & $-10.48 \%$ & $-16.41 \%$ \\
\hline 2036 & $-4.36 \%$ & $-8.52 \%$ & $-10.47 \%$ & $-16.33 \%$ \\
\hline 2037 & $-4.42 \%$ & $-7.53 \%$ & $-10.37 \%$ & $-17.07 \%$ \\
\hline 2038 & $-4.37 \%$ & $-7.40 \%$ & $-10.43 \%$ & $-17.19 \%$ \\
\hline 2039 & $-4.30 \%$ & $-8.43 \%$ & $-10.29 \%$ & $-16.07 \%$ \\
\hline 2040 & $-5.26 \%$ & $-8.41 \%$ & $-9.20 \%$ & $-15.99 \%$ \\
\hline 2041 & $-4.23 \%$ & $-7.44 \%$ & $-10.18 \%$ & $-16.91 \%$ \\
\hline 2042 & $-4.23 \%$ & $-8.36 \%$ & $-9.92 \%$ & $-15.75 \%$ \\
\hline 2043 & $-4.22 \%$ & $-8.39 \%$ & $-10.00 \%$ & $-15.75 \%$ \\
\hline 2044 & $-4.20 \%$ & $-8.33 \%$ & $-9.88 \%$ & $-15.55 \%$ \\
\hline 2045 & $-4.21 \%$ & $-8.27 \%$ & $-9.90 \%$ & $-15.44 \%$ \\
\hline 2046 & $-5.18 \%$ & $-8.27 \%$ & $-9.10 \%$ & $-15.66 \%$ \\
\hline 2047 & $-4.36 \%$ & $-7.47 \%$ & $-10.00 \%$ & $-16.43 \%$ \\
\hline 2048 & $-4.33 \%$ & $-8.41 \%$ & $-9.99 \%$ & $-15.46 \%$ \\
\hline 2049 & $-4.28 \%$ & $-8.35 \%$ & $-9.89 \%$ & $-15.32 \%$ \\
\hline 2050 & $-4.20 \%$ & $-8.27 \%$ & $-9.68 \%$ & $-15.13 \%$ \\
\hline 2051 & $-4.14 \%$ & $-8.15 \%$ & $-9.87 \%$ & $-15.19 \%$ \\
\hline 2052 & $-5.14 \%$ & $-8.06 \%$ & $-8.73 \%$ & $-14.98 \%$ \\
\hline 2053 & $-5.12 \%$ & $-8.00 \%$ & $-8.61 \%$ & $-14.81 \%$ \\
\hline 2054 & $-4.26 \%$ & $-7.19 \%$ & $-9.70 \%$ & $-15.75 \%$ \\
\hline 2055 & $-4.28 \%$ & $-8.19 \%$ & $-9.67 \%$ & $-14.85 \%$ \\
\hline 2056 & $-4.22 \%$ & $-8.14 \%$ & $-9.48 \%$ & $-14.64 \%$ \\
\hline 2057 & $-5.10 \%$ & $-8.11 \%$ & $-8.59 \%$ & $-14.68 \%$ \\
\hline 2058 & $-4.23 \%$ & $-7.30 \%$ & $-9.28 \%$ & $-15.38 \%$ \\
\hline 2059 & $-4.16 \%$ & $-8.20 \%$ & $-9.39 \%$ & $-14.71 \%$ \\
\hline 2060 & $-4.15 \%$ & $-8.28 \%$ & $-9.34 \%$ & $-14.63 \%$ \\
\hline
\end{tabular}


Table 5-5: The Impact of Policy 3 (More Distribution of the Cost to Governments)

\begin{tabular}{|c|c|c|c|c|c|c|}
\hline & \multicolumn{3}{|c|}{ Ratio to the Public Sector } & \multicolumn{3}{|c|}{ Ratio to the Public Sector } \\
\hline & $\begin{array}{c}50 \% \\
\text { (Benchmark) }\end{array}$ & $60 \%$ & $70 \%$ & $\begin{array}{c}50 \% \\
\text { (Benchmark) }\end{array}$ & $60 \%$ & $70 \%$ \\
\hline & \multicolumn{3}{|c|}{$\begin{array}{l}\text { The Fixed Amount of Monthly Contributions of } \\
\text { the First Group (age } 65 \text { and over) (Unit: yen) }\end{array}$} & \multicolumn{3}{|c|}{ Contribution Rate for the Second Group (age 40 - 64) } \\
\hline Year & & & & & & \\
\hline 2017 & 5,514 & 5,542 & 5,558 & $2.07 \%$ & $2.09 \%$ & $2.11 \%$ \\
\hline 2018 & 5,620 & 4,802 & 3,965 & $2.14 \%$ & $1.62 \%$ & $1.08 \%$ \\
\hline 2019 & 5,739 & 4,898 & 4,029 & $2.23 \%$ & $1.68 \%$ & $1.12 \%$ \\
\hline 2020 & 5,846 & 4,985 & 4,111 & $2.29 \%$ & $1.73 \%$ & $1.17 \%$ \\
\hline 2021 & 5,954 & 5,072 & 4,178 & $2.37 \%$ & $1.79 \%$ & $1.21 \%$ \\
\hline 2022 & 6,030 & 5,138 & 4,233 & $2.43 \%$ & $1.84 \%$ & $1.24 \%$ \\
\hline 2023 & 6,201 & 5,273 & 4,339 & $2.55 \%$ & $1.93 \%$ & $1.31 \%$ \\
\hline 2024 & 6,349 & 5,393 & 4,429 & $2.65 \%$ & $2.01 \%$ & $1.37 \%$ \\
\hline 2025 & 6,496 & 5,514 & 4,525 & $2.76 \%$ & $2.10 \%$ & $1.43 \%$ \\
\hline 2026 & 6,627 & 5,618 & 4,606 & $2.86 \%$ & $2.18 \%$ & $1.49 \%$ \\
\hline 2027 & 6,754 & 5,723 & 4,688 & $2.96 \%$ & $2.25 \%$ & $1.54 \%$ \\
\hline 2028 & 6,878 & 5,822 & 4,769 & $3.06 \%$ & $2.33 \%$ & $1.60 \%$ \\
\hline 2029 & 7,030 & 5,949 & 4,862 & $3.18 \%$ & $2.42 \%$ & $1.66 \%$ \\
\hline 2030 & 7,180 & 6,073 & 4,958 & $3.30 \%$ & $2.51 \%$ & $1.73 \%$ \\
\hline 2031 & 7,292 & 6,168 & 5,031 & $3.42 \%$ & $2.61 \%$ & $1.79 \%$ \\
\hline 2032 & 7,420 & 6,267 & 5,107 & $3.50 \%$ & $2.67 \%$ & $1.84 \%$ \\
\hline 2033 & 7,522 & 6,350 & 5,174 & $3.59 \%$ & $2.74 \%$ & $1.88 \%$ \\
\hline 2034 & 7,649 & 6,455 & 5,253 & $3.68 \%$ & $2.81 \%$ & $1.93 \%$ \\
\hline 2035 & 7,739 & 6,594 & 5,355 & $3.86 \%$ & $2.91 \%$ & $2.00 \%$ \\
\hline 2036 & 7,907 & 6,731 & 5,459 & $3.98 \%$ & $3.01 \%$ & $2.07 \%$ \\
\hline 2037 & 7,859 & 6,757 & 5,474 & $4.03 \%$ & $3.01 \%$ & $2.07 \%$ \\
\hline 2038 & 7,903 & 6,796 & 5,501 & $4.06 \%$ & $3.02 \%$ & $2.07 \%$ \\
\hline 2039 & 7,938 & 6,825 & 5,523 & $4.07 \%$ & $3.03 \%$ & $2.07 \%$ \\
\hline 2040 & 8,075 & 6,940 & 5,607 & $4.17 \%$ & $3.10 \%$ & $2.13 \%$ \\
\hline 2041 & 8,153 & 7,079 & 5,715 & $4.34 \%$ & $3.19 \%$ & $2.19 \%$ \\
\hline 2042 & 8,171 & 7,024 & 5,728 & $4.34 \%$ & $3.24 \%$ & $2.19 \%$ \\
\hline 2043 & 8,168 & 7,016 & 5,729 & $4.33 \%$ & $3.22 \%$ & $2.18 \%$ \\
\hline 2044 & 8,164 & 7,014 & 5,725 & $4.31 \%$ & $3.21 \%$ & $2.17 \%$ \\
\hline 2045 & 8,181 & 7,032 & 5,740 & $4.31 \%$ & $3.21 \%$ & $2.17 \%$ \\
\hline 2046 & 8,300 & 7,135 & 5,820 & $4.41 \%$ & $3.28 \%$ & $2.21 \%$ \\
\hline 2047 & 8,388 & 7,198 & 5,932 & $4.58 \%$ & $3.42 \%$ & $2.28 \%$ \\
\hline 2048 & 8,417 & 7,224 & 5,954 & $4.59 \%$ & $3.43 \%$ & $2.28 \%$ \\
\hline 2049 & 8,425 & 7,232 & 5,957 & $4.58 \%$ & $3.42 \%$ & $2.28 \%$ \\
\hline 2050 & 8,419 & 7,228 & 5,959 & $4.56 \%$ & $3.40 \%$ & $2.27 \%$ \\
\hline 2051 & 8,473 & 7,279 & 6,001 & $4.61 \%$ & $3.43 \%$ & $2.29 \%$ \\
\hline 2052 & 8,547 & 7,346 & 6,054 & $4.66 \%$ & $3.48 \%$ & $2.32 \%$ \\
\hline 2053 & 8,631 & 7,419 & 6,116 & $4.72 \%$ & $3.53 \%$ & $2.35 \%$ \\
\hline 2054 & 8,652 & 7,424 & 6,186 & $4.86 \%$ & $3.64 \%$ & $2.40 \%$ \\
\hline 2055 & 8,772 & 7,527 & 6,271 & $4.96 \%$ & $3.72 \%$ & $2.45 \%$ \\
\hline 2056 & 8,964 & 7,688 & 6,407 & $5.12 \%$ & $3.85 \%$ & $2.55 \%$ \\
\hline 2057 & 9,097 & 7,802 & 6,423 & $5.24 \%$ & $3.94 \%$ & $2.66 \%$ \\
\hline 2058 & 9,180 & 7,861 & 6,535 & $5.43 \%$ & $4.11 \%$ & $2.74 \%$ \\
\hline 2059 & 9,328 & 7,991 & 6,641 & $5.57 \%$ & $4.21 \%$ & $2.82 \%$ \\
\hline 2060 & 9,457 & 8,096 & 6,732 & $5.68 \%$ & $4.30 \%$ & $2.88 \%$ \\
\hline
\end{tabular}




\section{Table 5-6: The Impact of Policy 3 (Percentage changes from the benchmark)}

\begin{tabular}{|c|c|c|c|c|}
\hline & \multicolumn{2}{|c|}{ Ratio to the Public Sector } & \multicolumn{2}{|c|}{ Ratio to the Public Sector } \\
\hline & $60 \%$ & $70 \%$ & $60 \%$ & $70 \%$ \\
\hline & \multicolumn{2}{|c|}{$\begin{array}{l}\text { The Fixed Amount of Monthly Contributions of } \\
\text { the First Group (age } 65 \text { and over) (Unit: yen) }\end{array}$} & \multicolumn{2}{|c|}{ Contribution Rate for the Second Group (age $40-64$ ) } \\
\hline Year & & & & \\
\hline 2017 & $0.50 \%$ & $0.80 \%$ & $1.16 \%$ & $1.73 \%$ \\
\hline 2018 & $-14.56 \%$ & $-29.45 \%$ & $-24.38 \%$ & $-49.36 \%$ \\
\hline 2019 & $-14.65 \%$ & $-29.79 \%$ & $-24.51 \%$ & $-49.76 \%$ \\
\hline 2020 & $-14.73 \%$ & $-29.68 \%$ & $-24.26 \%$ & $-48.97 \%$ \\
\hline 2021 & $-14.82 \%$ & $-29.83 \%$ & $-24.28 \%$ & $-48.84 \%$ \\
\hline 2022 & $-14.80 \%$ & $-29.80 \%$ & $-24.28 \%$ & $-48.82 \%$ \\
\hline 2023 & $-14.97 \%$ & $-30.03 \%$ & $-24.22 \%$ & $-48.59 \%$ \\
\hline 2024 & $-15.06 \%$ & $-30.24 \%$ & $-24.04 \%$ & $-48.27 \%$ \\
\hline 2025 & $-15.11 \%$ & $-30.35 \%$ & $-24.00 \%$ & $-48.13 \%$ \\
\hline 2026 & $-15.22 \%$ & $-30.49 \%$ & $-23.90 \%$ & $-47.95 \%$ \\
\hline 2027 & $-15.26 \%$ & $-30.58 \%$ & $-23.90 \%$ & $-47.87 \%$ \\
\hline 2028 & $-15.35 \%$ & $-30.66 \%$ & $-23.87 \%$ & $-47.84 \%$ \\
\hline 2029 & $-15.38 \%$ & $-30.83 \%$ & $-23.81 \%$ & $-47.70 \%$ \\
\hline 2030 & $-15.41 \%$ & $-30.95 \%$ & $-23.91 \%$ & $-47.71 \%$ \\
\hline 2031 & $-15.42 \%$ & $-31.01 \%$ & $-23.62 \%$ & $-47.60 \%$ \\
\hline 2032 & $-15.53 \%$ & $-31.17 \%$ & $-23.73 \%$ & $-47.56 \%$ \\
\hline 2033 & $-15.58 \%$ & $-31.21 \%$ & $-23.76 \%$ & $-47.63 \%$ \\
\hline 2034 & $-15.61 \%$ & $-31.33 \%$ & $-23.58 \%$ & $-47.54 \%$ \\
\hline 2035 & $-14.79 \%$ & $-30.81 \%$ & $-24.60 \%$ & $-48.13 \%$ \\
\hline 2036 & $-14.87 \%$ & $-30.96 \%$ & $-24.44 \%$ & $-48.06 \%$ \\
\hline 2037 & $-14.02 \%$ & $-30.35 \%$ & $-25.27 \%$ & $-48.66 \%$ \\
\hline 2038 & $-14.00 \%$ & $-30.39 \%$ & $-25.61 \%$ & $-48.96 \%$ \\
\hline 2039 & $-14.02 \%$ & $-30.42 \%$ & $-25.55 \%$ & $-49.09 \%$ \\
\hline 2040 & $-14.05 \%$ & $-30.57 \%$ & $-25.61 \%$ & $-49.01 \%$ \\
\hline 2041 & $-13.17 \%$ & $-29.91 \%$ & $-26.50 \%$ & $-49.47 \%$ \\
\hline 2042 & $-14.04 \%$ & $-29.89 \%$ & $-25.37 \%$ & $-49.53 \%$ \\
\hline 2043 & $-14.10 \%$ & $-29.86 \%$ & $-25.52 \%$ & $-49.71 \%$ \\
\hline 2044 & $-14.09 \%$ & $-29.88 \%$ & $-25.51 \%$ & $-49.72 \%$ \\
\hline 2045 & $-14.05 \%$ & $-29.84 \%$ & $-25.52 \%$ & $-49.76 \%$ \\
\hline 2046 & $-14.03 \%$ & $-29.87 \%$ & $-25.69 \%$ & $-49.81 \%$ \\
\hline 2047 & $-14.18 \%$ & $-29.28 \%$ & $-25.25 \%$ & $-50.16 \%$ \\
\hline 2048 & $-14.17 \%$ & $-29.27 \%$ & $-25.32 \%$ & $-50.24 \%$ \\
\hline 2049 & $-14.16 \%$ & $-29.29 \%$ & $-25.34 \%$ & $-50.25 \%$ \\
\hline 2050 & $-14.14 \%$ & $-29.22 \%$ & $-25.33 \%$ & $-50.25 \%$ \\
\hline 2051 & $-14.10 \%$ & $-29.18 \%$ & $-25.50 \%$ & $-50.34 \%$ \\
\hline 2052 & $-14.05 \%$ & $-29.17 \%$ & $-25.38 \%$ & $-50.26 \%$ \\
\hline 2053 & $-14.04 \%$ & $-29.14 \%$ & $-25.29 \%$ & $-50.12 \%$ \\
\hline 2054 & $-14.20 \%$ & $-28.50 \%$ & $-25.03 \%$ & $-50.65 \%$ \\
\hline 2055 & $-14.20 \%$ & $-28.51 \%$ & $-24.90 \%$ & $-50.54 \%$ \\
\hline 2056 & $-14.24 \%$ & $-28.53 \%$ & $-24.75 \%$ & $-50.25 \%$ \\
\hline 2057 & $-14.24 \%$ & $-29.40 \%$ & $-24.78 \%$ & $-49.20 \%$ \\
\hline 2058 & $-14.36 \%$ & $-28.81 \%$ & $-24.39 \%$ & $-49.49 \%$ \\
\hline 2059 & $-14.34 \%$ & $-28.80 \%$ & $-24.44 \%$ & $-49.45 \%$ \\
\hline 2060 & $-14.40 \%$ & $-28.82 \%$ & $-24.30 \%$ & $-49.35 \%$ \\
\hline
\end{tabular}


Table 5-7: The Impact of Policy 3 on the Consumption Tax Rate

\begin{tabular}{|c|c|c|c|c|c|}
\hline & \multicolumn{3}{|c|}{ Ratio to the Public Sector } & \multicolumn{2}{|c|}{ Ratio to the Public Sector } \\
\hline & $50 \%$ (Benchmark) & $60 \%$ & $70 \%$ & $60 \%$ & $70 \%$ \\
\hline & \multicolumn{3}{|c|}{ Consumption Tax Rate } & \multicolumn{2}{|c|}{$\begin{array}{l}\% \text { change in the consumption tax rate from } \\
\text { the benchmark rate }\end{array}$} \\
\hline Year & & & & & \\
\hline 2017 & $8.00 \%$ & $8.00 \%$ & $8.00 \%$ & $0.00 \%$ & $0.00 \%$ \\
\hline 2018 & $8.00 \%$ & $8.00 \%$ & $8.00 \%$ & $0.00 \%$ & $0.00 \%$ \\
\hline 2019 & $8.40 \%$ & $9.57 \%$ & $9.96 \%$ & $14.02 \%$ & $18.55 \%$ \\
\hline 2020 & $7.90 \%$ & $9.01 \%$ & $10.10 \%$ & $14.01 \%$ & $27.75 \%$ \\
\hline 2021 & $8.13 \%$ & $9.27 \%$ & $10.40 \%$ & $14.09 \%$ & $27.97 \%$ \\
\hline 2022 & $7.64 \%$ & $8.83 \%$ & $10.01 \%$ & $15.61 \%$ & $31.02 \%$ \\
\hline 2023 & $8.11 \%$ & $9.35 \%$ & $10.57 \%$ & $15.24 \%$ & $30.32 \%$ \\
\hline 2024 & $8.28 \%$ & $9.57 \%$ & $10.85 \%$ & $15.61 \%$ & $31.07 \%$ \\
\hline 2025 & $11.82 \%$ & $13.18 \%$ & $14.53 \%$ & $11.53 \%$ & $22.97 \%$ \\
\hline 2026 & $12.59 \%$ & $14.00 \%$ & $15.42 \%$ & $11.23 \%$ & $22.44 \%$ \\
\hline 2027 & $13.33 \%$ & $14.79 \%$ & $16.26 \%$ & $10.98 \%$ & $21.98 \%$ \\
\hline 2028 & $13.87 \%$ & $15.39 \%$ & $16.92 \%$ & $10.94 \%$ & $21.92 \%$ \\
\hline 2029 & $14.41 \%$ & $15.99 \%$ & $17.57 \%$ & $10.95 \%$ & $21.93 \%$ \\
\hline 2030 & $14.93 \%$ & $16.57 \%$ & $18.21 \%$ & $10.97 \%$ & $21.97 \%$ \\
\hline 2031 & $15.34 \%$ & $17.03 \%$ & $18.73 \%$ & $11.02 \%$ & $22.13 \%$ \\
\hline 2032 & $15.78 \%$ & $17.52 \%$ & $19.27 \%$ & $11.01 \%$ & $22.13 \%$ \\
\hline 2033 & $16.30 \%$ & $18.10 \%$ & $19.91 \%$ & $11.01 \%$ & $22.14 \%$ \\
\hline 2034 & $16.94 \%$ & $18.80 \%$ & $20.68 \%$ & $11.00 \%$ & $22.10 \%$ \\
\hline 2035 & $17.68 \%$ & $19.63 \%$ & $21.58 \%$ & $11.01 \%$ & $22.08 \%$ \\
\hline 2036 & $18.43 \%$ & $20.46 \%$ & $22.50 \%$ & $10.97 \%$ & $22.05 \%$ \\
\hline 2037 & $19.05 \%$ & $21.13 \%$ & $23.22 \%$ & $10.92 \%$ & $21.93 \%$ \\
\hline 2038 & $19.66 \%$ & $21.79 \%$ & $23.95 \%$ & $10.88 \%$ & $21.86 \%$ \\
\hline 2039 & $20.22 \%$ & $22.41 \%$ & $24.63 \%$ & $10.84 \%$ & $21.84 \%$ \\
\hline 2040 & $20.83 \%$ & $23.10 \%$ & $25.40 \%$ & $10.91 \%$ & $21.97 \%$ \\
\hline 2041 & $21.41 \%$ & $23.77 \%$ & $26.16 \%$ & $11.00 \%$ & $22.17 \%$ \\
\hline 2042 & $21.81 \%$ & $24.21 \%$ & $26.66 \%$ & $10.97 \%$ & $22.20 \%$ \\
\hline 2043 & $22.14 \%$ & $24.57 \%$ & $27.06 \%$ & $10.96 \%$ & $22.22 \%$ \\
\hline 2044 & $22.42 \%$ & $24.89 \%$ & $27.42 \%$ & $10.98 \%$ & $22.26 \%$ \\
\hline 2045 & $22.70 \%$ & $25.20 \%$ & $27.77 \%$ & $11.03 \%$ & $22.37 \%$ \\
\hline 2046 & $23.06 \%$ & $25.63 \%$ & $28.28 \%$ & $11.13 \%$ & $22.61 \%$ \\
\hline 2047 & $23.48 \%$ & $26.12 \%$ & $28.85 \%$ & $11.23 \%$ & $22.86 \%$ \\
\hline 2048 & $23.73 \%$ & $26.41 \%$ & $29.18 \%$ & $11.28 \%$ & $22.96 \%$ \\
\hline 2049 & $23.95 \%$ & $26.66 \%$ & $29.46 \%$ & $11.32 \%$ & $23.04 \%$ \\
\hline 2050 & $24.14 \%$ & $26.88 \%$ & $29.72 \%$ & $11.36 \%$ & $23.14 \%$ \\
\hline 2051 & $24.40 \%$ & $27.19 \%$ & $30.09 \%$ & $11.45 \%$ & $23.33 \%$ \\
\hline 2052 & $24.70 \%$ & $27.54 \%$ & $30.50 \%$ & $11.52 \%$ & $23.50 \%$ \\
\hline 2053 & $25.02 \%$ & $27.92 \%$ & $30.95 \%$ & $11.58 \%$ & $23.66 \%$ \\
\hline 2054 & $25.39 \%$ & $28.34 \%$ & $31.44 \%$ & $11.65 \%$ & $23.83 \%$ \\
\hline 2055 & $25.83 \%$ & $28.86 \%$ & $32.02 \%$ & $11.72 \%$ & $23.95 \%$ \\
\hline 2056 & $26.42 \%$ & $29.54 \%$ & $32.79 \%$ & $11.80 \%$ & $24.12 \%$ \\
\hline 2057 & $26.97 \%$ & $30.17 \%$ & $33.50 \%$ & $11.84 \%$ & $24.18 \%$ \\
\hline 2058 & $27.61 \%$ & $30.89 \%$ & $34.32 \%$ & $11.88 \%$ & $24.29 \%$ \\
\hline 2059 & $28.29 \%$ & $31.66 \%$ & $35.17 \%$ & $11.90 \%$ & $24.32 \%$ \\
\hline 2060 & $28.97 \%$ & $32.41 \%$ & $36.02 \%$ & $11.88 \%$ & $24.32 \%$ \\
\hline
\end{tabular}




\section{Figure 5-1: Welfare}

\section{Welfare (Consumption Equivalence)}

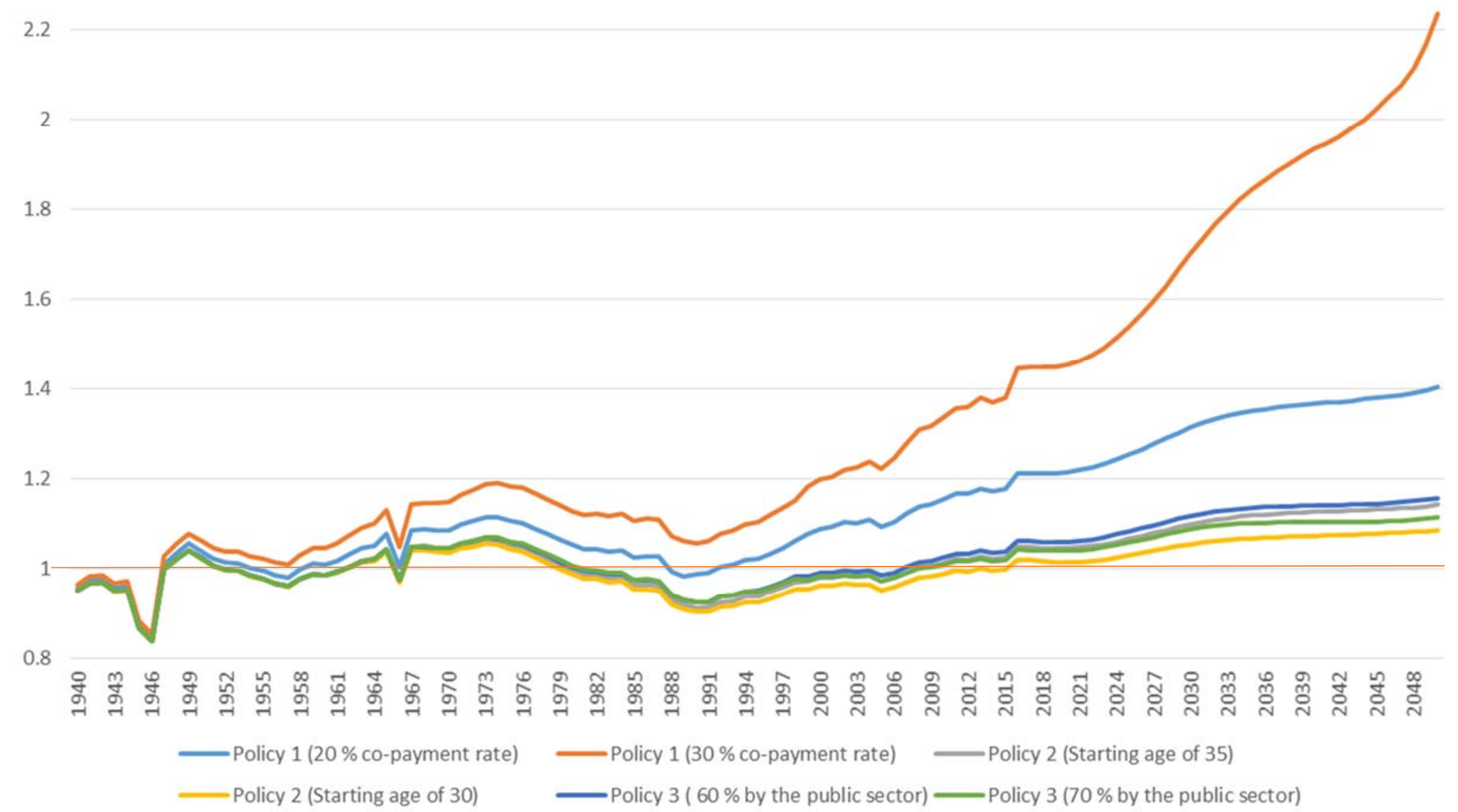


Figure 5-2: Welfare

Welfare (Consumption Equivalence)

1.2

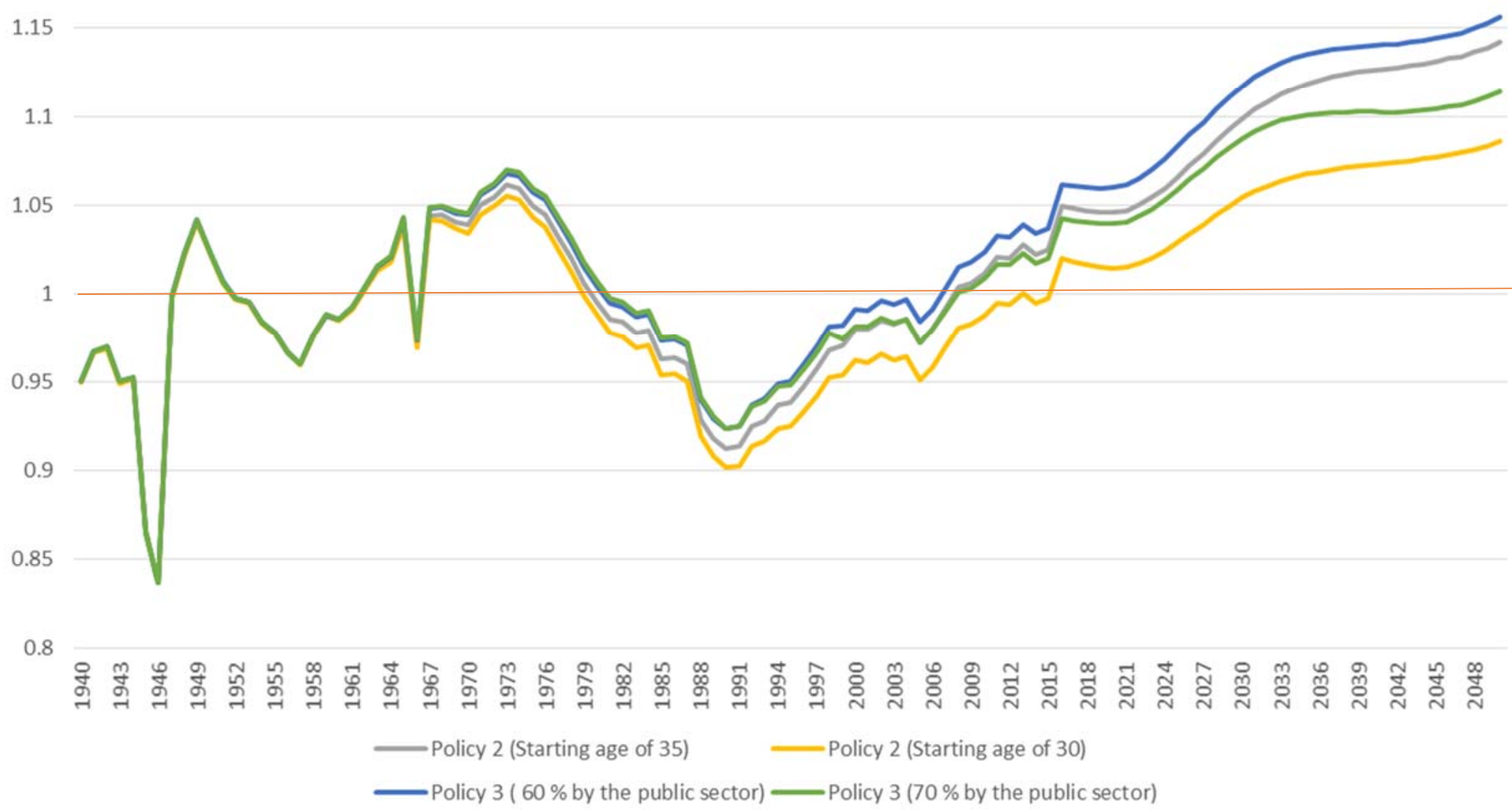

